\title{
Rechtliche Grundlagen der Verrechnungspreise
}

\author{
Susanne Tomson und Claas Buurman
}

\subsection{Einleitung}

Die in diesem Buch dargestellten Verfahren zur Ermittlung konzerninterner Verrechnungspreise beruhen auf nationalen sowie internationalen gesetzlichen Regelungen bzw. völkerrechtlichen Verträgen und verpflichten den Steuerpflichtigen ebenso wie die beteiligten Finanzverwaltungen. Ohne bindende Vorschriften, die sowohl den Steuerpflichtigen als auch die Finanzverwaltung zur Anwendung des Fremdvergleichsgrundsatzes verpflichten, ist kein Steuerpflichtiger dazu gezwungen, den Fremdvergleich bei seiner steuerlichen Gewinnermittlung anzuwenden. Ebenso wie die Anwendung der „Grundsätze ordnungsmäßiger Buchführung“ für Kaufleute aufgrund gesetzlicher Regelungen verpflichtend ist ${ }^{1}$, bedarf es somit auch für die Anwendung des Fremdvergleichsgrundsatzes gesetzlicher Regelungen.

Der Fremdvergleichsgrundsatz als Maßstab der internationalen Gewinnabgrenzung ist in den international zwischen den einzelnen Staaten abgeschlossenen Doppelbesteurungsabkommen kodifiziert. Diese Doppelbesteuerungsabkommen stellen völkerrechtliche Verträge dar und regeln die Aufteilung von Besteuerungsrechten zwischen einzelnen Staaten. Um eine relative Homogenität dieser bilateralen Verträge sicherzustellen, sind im Rahmen internationaler Organisationen Musterformulierungen für diese bilateralen

${ }^{1}$ Vgl. $\S 238$ HGB.

C. Buurman $(\bowtie)$

Deloitte \& Touche GmbH Wirtschaftsprüfungsgesellschaft, Kurfürstendamm 23, 10719 Berlin, Deutschland

E-Mail: clbuurman@deloitte.de

S. Tomson

PricewaterhouseCoopers AG Wirtschaftsprüfungsgesellschaft, Konrad-Adenauer-Ufer 11, 50668

Köln, Deutschland

E-Mail: susanne.tomson@de.pwc.com

(C) Der/die Herausgeber bzw. der/die Autor(en) 2016

R. Dawid (Hrsg.), Verrechnungspreise, DOI 10.1007/978-3-658-09377-8_2 
Doppelbesteuerungsabkommen entwickelt worden. Es existieren u. a. folgende wichtige Musterabkommen:

- Musterabkommen der OECD

- Musterabkommen der UN

Neben Unterschieden, die insbesondere zwischen dem Musterabkommen der OECD und dem Musterabkommen der UN in einer unterschiedlichen Aufteilung von Besteuerungsrechten bestehen, ist der Fremdvergleichsgrundsatz in sämtlichen Musterabkommen kodifiziert. Der Fremdvergleichsgrundsatz gem. Art. 9 OECD-MA lautet wie folgt:

,Wenn

a. ein Unternehmen eines Vertragsstaats unmittelbar oder mittelbar an der Geschäftsleitung, der Kontrolle oder dem Kapital eines Unternehmens des anderen Vertragsstaats beteiligt ist, oder

b. dieselben Personen unmittelbar oder mittelbar an der Geschäftsleitung, der Kontrolle oder dem Kapital eines Unternehmens eines Vertragsstaats und eines Unternehmens des anderen Vertragsstaats beteiligt sind

und in diesen Fällen die beiden Unternehmen in ihren kaufmännischen oder finanziellen Beziehungen an vereinbarte oder auferlegte Bedingungen gebunden sind, die von denen abweichen, die unabhängige Unternehmen miteinander vereinbaren würden, so dürfen die Gewinne, die eines der Unternehmen ohne diese Bedingungen erzielt hätte, wegen dieser Bedingungen aber nicht erzielt hat, den Gewinnen dieses Unternehmens zugerechnet und entsprechend besteuert werden."

Auch die von der Bundesrepublik Deutschland abgeschlossenen Doppelbesteuerungsabkommen beinhalten - gegebenenfalls mit redaktionellen Unterschieden - diesen Fremdvergleichsgrundsatz. Bei Abschluss eines Doppelbesteuerungsabkommens, das einen dem Art. 9 OECD-MA entsprechenden Artikel beinhaltet, verpflichtet sich die Bundesrepublik Deutschland insoweit gegenüber dem anderen Vertragsstaat dazu, den Fremdvergleichsgrundsatz einzuhalten.

Die bilateral zwischen der Bundesrepublik Deutschland und den beteiligten Staaten abgeschlossenen Doppelbesteuerungsabkommen stellen keine steuerbegründenden Normen dar. Stattdessen begrenzen sie das Besteuerungsrecht der beteiligten Staaten. ${ }^{2}$ Zudem ist der Fremdvergleichsgrundsatz in den jeweiligen Doppelbesteuerungsabkommen so ausgestaltet, dass er keine alleinige Rechtsgrundlage für eine Gewinnberichtigung darstellt. Dementsprechend bedarf es innerstaatlicher Normen zur Umsetzung des Fremdvergleichsgrundsatzes in der Bundesrepublik Deutschland. Sollte zwischen der Bundesrepublik Deutschland und dem betreffenden Staat kein Doppelbesteuerungsabkommen

${ }^{2}$ Vgl. Vögele/Fischer in Vögele/Borstell/Engler, Verrechnungspreise, Kapitel A, Rn. 13. 
bestehen (wie beispielsweise mit Wirkung zum 01.01.2006 mit Brasilien) kommen ausschließlich innerstaatliche Normen zur Anwendung.

Diese innerstaatlichen Normen können Gesetze sein. Neben Gesetzen zählen zu den innerstaatlichen Normen, die den Steuerpflichtigen und die Finanzverwaltung binden, auch Rechtsverordnungen. Rechtsverordnungen werden im Bereich der Verrechnungspreise durch das Bundesministerium der Finanzen mit Zustimmung des Bundesrats erlassen. Es bedarf hierzu jeweils einer gesetzlichen Regelung, und die Rechtsverordnungen können nur in dem vom Gesetz definierten Rahmen erlassen werden. Für den Bereich der Verrechnungspreise sind gegenwärtig folgende Rechtsverordnungen in Kraft:

- Verordnung zu Art, Inhalt und Umfang von Aufzeichnungen im Sinne des $§ 90$ Abs. 3 der Abgabenordnung (Gewinnabgrenzungsaufzeichnungsverordnung - GAufzV) vom 13.11.2003 i. d. F.26.6.2013

- Verordnung zur Anwendung des Fremdvergleichsgrundsatzes nach $\S 1$ Abs. 1 des Außensteuergesetzes in Fällen grenzüberschreitender Funktionsverlagerungen (Funktionsverlagerungsverordnung - FVerlV) v. 12.08.2008 i. d. F. v. 26.6.2013

- Verordnung zur Anwendung des Fremdvergleichsgrundsatzes auf Betriebsstätten nach $\S 1$ Abs. 5 des Außensteuergesetzes (Betriebsstättengewinnaufteilungsverordnung BsGaV) vom 13. Oktober 2014

Zudem wird seitens des Bundesministeriums der Finanzen gegenwärtig an einer Rechtsverordnung zu Einzelheiten und zur Anwendung des Fremdvergleichsgrundsatzes gearbeitet. Rechtsgrundlage dieser Rechtsverordnung ist $\S 1$ Abs. 6 des AStG. Bislang liegt allerdings noch kein öffentlicher Entwurf dieser Rechtsverordnung vor.

Bei Rechtsverordnungen werden Teile der Exekutive dazu ermächtigt, mit Zustimmung des Bundesrats weitergehende Verordnungen über einen eng begrenzten und im Gesetz definierten Rahmen zu erlassen. Insofern stellt sich hierbei die Frage, ob die teilweise sehr weitgehenden Rechtsverordnungen noch in Einklang mit der jeweiligen Ermächtigung stehen, da die Voraussetzung für den Erlass einer Rechtsverordnung die vorausgehende Ermächtigung ist. Wir werden im Folgenden von weitergehenden Diskussionen dieser Problematik absehen. Steuerpflichtige sollten jedoch im Einzelfall gegebenenfalls prüfen (lassen), ob einseitig belastende Regelungen der Verordnungen im Rechtswege angegriffen werden können.

Neben diesen den Steuerpflichtigen sowie die Finanzverwaltung bindenden Normen hat die Finanzverwaltung zudem eine Vielzahl von Verwaltungsanweisungen erlassen, die die Auffassung der Finanzverwaltung zu den wichtigsten Verrechnungspreisthemen darlegen. Diese Verwaltungsanweisungen binden ausschließlich die Finanzverwaltung und weder den Steuerpflichtigen noch die Gerichte. Dementsprechend ist es insbesondere in Betriebsprüfungen von entscheidender Bedeutung, die Rechtsgrundlage hinter der von der Finanzverwaltung vertretenen Rechtsauffassung zu kennen. Es gilt insofern zu verhindern, dass in den Verwaltungsanweisungen dargelegte Rechtsauffassungen ungeprüft als geltendes Recht aufgefasst werden. 
Die wichtigsten im Zusammenhang mit grenzüberschreitenden Verrechnungspreisen ergangenen Verwaltungsanweisungen sind in chronologischer Reihenfolge:

- Grundsätze für die Prüfung der Einkunftsabgrenzung bei international verbundenen Unternehmen (Verwaltungsgrundsätze) v. 23.02.1983

- Grundsätze der Verwaltung für die Prüfung der Aufteilung der Einkünfte bei Betriebsstätten international tätiger Unternehmen (Betriebsstätten-Verwaltungsgrundsätze) v. 24.12.1999

- Grundsätze für die Prüfung der Einkunftsabgrenzung durch Umlageverträge zwischen international verbundenen Unternehmen (VWG-Umlageverträge) v. 30.12.1999 - veraltet aufgrund $\mathrm{BsGaV}$

- Grundsätze für die Prüfung der Einkunftsabgrenzung zwischen international verbundenen Unternehmen in Fällen der Arbeitnehmerentsendung (VerwaltungsgrundsätzeArbeitnehmerentsendung) v. 09.11.2001

- Grundsätze zur Anwendung des Außensteuergesetzes (Anwendungsschreiben zum AStG) v. 14.05.2004

- Grundsätze für die Prüfung der Einkunftsabgrenzung zwischen nahestehenden Personen mit grenzüberschreitenden Geschäftsbeziehungen in Bezug auf Ermittlungs- und Mitwirkungspflichten, Berichtigungen sowie auf Verständigungs- und EU-Schiedsverfahren (VWGV) v. 12.04.2005

- Merkblatt zur zwischenstaatlichen Amtshilfe durch Informationsaustausch in Steuersachen v. 25.01.2006

- Merkblatt zum internationalen Verständigungs- und Schiedsverfahren auf dem Gebiet der Steuern vom Einkommen und vom Vermögen v. 13.07.2006

- Merkblatt für bilaterale oder multilaterale Vorabverständigungsverfahren auf der Grundlage der Doppelbesteuerungsabkommen zur Erteilung verbindlicher Vorabzusagen über Verrechnungspreise zwischen international verbundenen Unternehmen (sog. „Advance Pricing Agreements“ - APAs) v. 05.10.2006

- Grundsätze für die Prüfung der Einkunftsabgrenzung zwischen nahe stehenden Personen in Fällen von grenzüberschreitenden Funktionsverlagerungen (Verwaltungsgrundsätze Funktionsverlagerung) v. 13.10.2010

Innerhalb dieses Kapitels werden wichtige innerstaatliche Korrekturvorschriften kurz dargestellt. Zudem wird ein Überblick über die OECD-Doppelbesteuerungsabkommen und die OECD-RL sowie für den Steuerpflichtigen praktisch sehr bedeutenden Mitwirkungspflichten, insbesondere die gesetzlichen Dokumentationspflichten gem. § 90 Abs. 3 AO in Verbindung mit der GAufzV gegeben. Abschließend beschäftigt sich dieses Kapitel mit den Möglichkeiten einer Vermeidung der Doppelbesteuerung mittels Verständigungs- und Schiedsverfahren sowie APAs. 


\subsection{Nationale Korrekturvorschriften}

Bei den nationalen steuerlichen Regelungen ist zwischen Korrekturnormen zu unterscheiden, die sowohl für inländische als auch für grenzüberschreitende Sachverhalte gelten und Korrekturnormen, die ausschließlich auf grenzüberschreitende Sachverhalte Anwendung finden.

Sowohl auf inländische als auch auf ausländische Sachverhalte finden die folgenden Korrekturnormen Anwendung:

- Entnahme gem. $\S 4$ Abs. 1 S. 2 EStG

- Einlage gem. $\S 4$ Abs. 1 S. 8 EStG

- Verdeckte Einlage gem. $\S 8$ Abs. 3 S. 3 KStG

- Verdeckte Gewinnausschüttung gem. $\S 8$ Abs. 3 S. 2 KStG

Sowohl die Entnahme als auch die Einlage finden auf Mitunternehmerschaften bzw. Einzelunternehmen Anwendung. Die Regelungen zur verdeckten Einlage sowie zur verdeckten Gewinnausschüttung finden auf Kapitalgesellschaften Anwendung. Zur Ergänzung dieser innerstaatlichen Korrekturnormen, die sowohl auf nationale als auch auf internationale Sachverhalte Anwendung finden, ist das AStG explizit als Korrekturnorm für grenzüberschreitende Sachverhalte entwickelt worden. Hintergrund der Verabschiedung des AStG am 08.09.1972 war die Bekämpfung steuerlicher Gewinnverlagerungen ins Ausland. ${ }^{3}$ Als Missbrauchsbekämpfungsvorschrift ist $\S 1$ AStG zudem nur dann anzuwenden, wenn die Einkünfte des Steuerpflichtigen in Deutschland aufgrund nicht zutreffender Verrechnungspreise gemindert worden sind. Für den korrespondierenden Fall einer Erhöhung der Einkünfte des Steuerpflichtigen aufgrund unangemessener Verrechnungspreise ist $\S 1$ AStG nicht anzuwenden. Jedoch vertritt die Finanzverwaltung in den VWG-FVerl die Auffassung, dass die VWG-FVerl korrespondierend auch für Funktionsverlagerungen ins Inland gelten sollen.

Das AStG regelt in $\S 1$ AStG die Anwendung des Fremdvergleichsgrundsatzes im innerstaatlichen Recht. Seit Änderung des § 1 AStG zum Veranlagungszeitraum 2008 gilt, dass $§ 1$ AStG ergänzend zu den sonstigen nationalen Regelungen zur Anwendung kommt.

Wie bereits dargestellt, bestehen neben den gesetzlichen Regelungen auch Rechtsverordnungen zum Thema Verrechnungspreise, welche die bestehenden Gesetze konkretisieren und ebenfalls Gesetzesrang haben, also dementsprechend auch für nationale Gerichte bindend sind. Bezüglich der Regelungen zum Fremdvergleichsgrundsatz nach $\S 1 \mathrm{AStG}$ ist dies gegenwärtig die FVerlV und die $\mathrm{BsGaV}$.

${ }^{3}$ Vgl. zur Entstehungsgeschichte des AStG Wassermeyer, AStG Kommentar, § 1 Anm. 16 ff. 


\subsubsection{Entnahme/Einlage}

Entnahmen sind nach der Definition von $\S 4$ Abs. 1 Satz 2 EStG alle Wirtschaftsgüter (Barentnahmen, Waren, Erzeugnisse, Nutzungen und Leistungen), die der Steuerpflichtige dem Betrieb für sich, für seinen Haushalt oder für andere betriebsfremde Zwecke im Laufe des Wirtschaftsjahrs entnommen hat. Bei Werten, die außerbetrieblich erwirtschaftet und dem Betriebsvermögen zugeführt wurden, handelt es sich um Einlagen, § 4 Abs. 1 Satz 1 EStG. Gegenstand von Einlagen können abnutzbare und nicht abnutzbare, materielle und immaterielle Wirtschaftsgüter aller Art sein, unabhängig davon, ob sie dem Anlage- oder dem Umlaufvermögen zuzuordnen sind (R 4.3 Abs. 1 EStR).

Auf Einzelunternehmen und Personengesellschaften finden die Regelungen zur Entnahme bzw. zur Einlage Anwendung. Grundsätzlich gilt, dass Entnahmen bzw. Einlagen mit dem Teilwert zu bewerten sind. Der Teilwert gilt als der Betrag, den der Erwerber des ganzen Betriebs im Rahmen eines Gesamtkaufpreises dem erworbenen Wirtschaftsgut zuschreiben würde. ${ }^{4}$ Eine Entnahme bzw. Einlage wird immer dann angenommen, wenn ein Wirtschaftsgut aus der betrieblichen Sphäre des Steuerpflichtigen in die private Sphäre des Steuerpflichtigen übergeht oder umgekehrt.

Die Definition des Teilwerts führt dazu, dass in vielen Fällen eine Schätzung des Teilwerts notwendig ist. Die Obergrenze des Schätzungsrahmens bilden die Wiederbeschaffungskosten, die Untergrenze die Netto-Einzelveräußerungspreise. Als Wiederbeschaffungskosten ist der Betrag anzusehen, der für die Anschaffung des Wirtschaftsguts in gleicher Güte und Beschaffenheit am Bewertungsstichtag aufzuwenden wäre. ${ }^{5}$ Gewinnaufschläge dürfen bei der Bewertung nicht berücksichtigt werden. Für selbst erstellte Wirtschaftsgüter entspricht der Teilwert daher bspw. den Reproduktionskosten, also sämtlichen Herstellungskosten einschließlich anteiliger Gemeinkosten, zuzüglich etwaiger kalkulatorischer Zusatzkosten. Zwischen dem Teilwert und dem Fremdvergleichspreis können im konkreten Einzelfall somit erhebliche Unterschiede bestehen. Andererseits wird sich eine Übereinstimmung hinsichtlich des Teilwertes von fremd erworbenen Wirtschaftsgütern und dem Fremdvergleichspreis ergeben. ${ }^{6}$

Zudem ist gesetzlich fixiert, dass auch „der Ausschluss oder die Beschränkung des Besteuerungsrechts der Bundesrepublik Deutschland hinsichtlich des Gewinns aus der Veräußerung oder der Nutzung eines Wirtschaftsguts“ einer Entnahme gleichsteht (Entstrickung). Dies gilt insbesondere dann, wenn ein Wirtschaftsgut anstelle einer inländischen einer ausländischen Betriebsstätte zuzuordnen ist. ${ }^{7}$ Korrespondierend gilt auch die Zuordnung von Wirtschaftsgütern, die anstelle einer ausländischen Betriebsstätte jetzt einer inländischen Betriebsstätte zuzuordnen sind, als Einlage (Verstrickung). ${ }^{8}$

\footnotetext{
${ }^{4}$ Vgl. § 6 Abs. 1 Nr. 1 S. 3 EStG.

${ }^{5}$ Vgl. Vögele/Fischer in Vögele/Borstell/Engler, Verrechnungspreise, Kapitel A Rn. 36.

${ }^{6}$ Vgl. Vögele/Fischer in Vögele/Borstell/Engler, Verrechnungspreise, Kapitel A Rn. 37.

${ }^{7}$ Vgl. $\S 4$ Abs. 1 S. 3 und 4 EStG.

8 Vgl. $\$ 4$ Abs. 1 S. 8 EStG.
} 
Für Zwecke der Überführung von Wirtschaftsgütern in eine Betriebsstätte wird als Bewertungsmaßstab nicht der Teilwert, sondern der gemeine Wert angesetzt. Der gemeine Wert bezeichnet den Wert, den ein fremder Dritter für dieses Wirtschaftsgut als Einzelveräußerungspreis bezahlen würde. ${ }^{9}$ Dieser Preis beinhaltet insofern im Gegensatz zum Teilwert auch ein Gewinnelement.

Zur Abmilderung der potenziellen EU-Rechtswidrigkeit dieser Regelung, da Verlagerungen von Wirtschaftsgütern innerhalb eines Unternehmens in andere EU-Staaten gegenüber einer Verlagerung dieser Wirtschaftsgüter innerhalb Deutschlands benachteiligt sind, kann für den Fall der Verlagerung eines Wirtschaftsguts in das EU-Ausland für den entstehenden Gewinn, der aufgrund der Bewertung nach dem gemeinen Wert entsteht (sofern dieser auf das Anlagevermögen entfällt) ein steuerneutraler Ausgleichsposten gebildet werden.

Dieser Ausgleichsposten ist im Jahr der Bildung und den darauf folgenden vier Jahren zu gleichen Teilen gewinnerhöhend aufzulösen. ${ }^{10}$ Wird das Wirtschaftsgut innerhalb von fünf Jahren nach Änderung der Zuordnung wieder einer deutschen Betriebsstätte des Steuerpflichtigen zugeordnet, sind die erhöhten Anschaffungskosten des Wirtschaftsguts sowie die gewinnerhöhenden Auflösungen des Ausgleichspostens zu korrigieren. ${ }^{11}$ Dementsprechend wird die Gewinnerhöhung in diesen Fällen wieder rückgängig gemacht.

Auch für Kapitalgesellschaften gilt, dass eine vorstehend dargestellte Änderung der Zuordnung eines Wirtschaftsguts eine Gewinnrealisierung zum gemeinen Wert darstellt. In diesem Fall wird die Veräußerung oder Überlassung des Wirtschaftsguts zum gemeinen Wert fingiert, die Regelungen des $\S 4 \mathrm{~g} \mathrm{EStG}$ gelten entsprechend. ${ }^{12}$

\subsubsection{Verdeckte Einlage}

Kapitalgesellschaften haben ausschließlich eine betriebliche Sphäre. Eine Trennung in eine private und eine betriebliche Sphäre, wie sie bei Einzelunternehmen und Personengesellschaften vorgenommen wird, ist insofern nicht möglich. Dementsprechend finden auch die Regelungen zur Einlage/Entnahme auf Kapitalgesellschaften keine Anwendung.

Für Kapitalgesellschaften können jedoch die Regelungen zur verdeckten Einlage i. S. d. $\S 8$ Abs. 3 S. 3 KStG Anwendung finden. Eine verdeckte Einlage liegt vor, ,wenn ein Gesellschafter oder eine ihm nahestehende Person der Körperschaft außerhalb der gesellschaftsrechtlichen Einlagen einen einlagefähigen Vermögensvorteil zuwendet und diese Zuwendung durch das Gesellschaftsverhältnis veranlasst ist" ${ }^{\text {" }}{ }^{13}$

\footnotetext{
${ }^{9}$ Vgl. § 9 Abs. 2 BewG.

${ }^{10} \mathrm{Vgl} . \S 4$ g Abs. 2 EStG.

${ }^{11} \mathrm{Vgl} . \S 4$ g Abs. 3 EStG.

${ }^{12} \mathrm{Vgl}$. § 12 Abs. $1 \mathrm{KStG}$.

${ }^{13} \mathrm{Vgl}$. R40 KStR.
} 
Die Rechtsfolge einer verdeckten Einlage ist, dass diese den Gewinn der Kapitalgesellschaft, in welche eingelegt worden ist, nicht erhöht, obwohl die verdeckte Einlage das Vermögen der Gesellschaft erhöht hat. ${ }^{14}$ Die verdeckte Einlage ist mit dem Teilwert zu bewerten. ${ }^{15}$ Die verdeckte Einlage ist auch bei dem einlegenden Gesellschafter mit dem Teilwert zu bewerten und erhöht somit dessen Einkommen sowie dessen Anschaffungskosten der Beteiligung an der Kapitalgesellschaft. Zudem wird durch die verdeckte Einlage das steuerliche Einlagekonto der Kapitalgesellschaft gem. § $27 \mathrm{KStG}$ erhöht.

Bei der Anwendung der Regelung zur verdeckten Einlage ist zu beachten, dass nur einlagefähige Wirtschaftsgüter Teil einer verdeckten Einlage sein können. Dementsprechend stellt die Überlassung von Nutzungsvorteilen des Gesellschafters an seine Kapitalgesellschaft (bspw. unentgeltliche Tätigkeiten seines Personals, Überlassung von Darlehen zu einem unüblich niedrigen Zinssatz) keine verdeckten Einlagen dar. Bei nicht grenzüberschreitenden Geschäftsvorfällen greift insoweit keine ertragssteuerliche Korrekturnorm. Im Falle grenzüberschreitender Geschäftsvorfälle sind diese Geschäftsbeziehungen jedoch regelmäßig Gegenstand einer Korrektur gem. § $1 \mathrm{AStG}$.

Durch das Jahressteuergesetz 2007 wurden für verdeckte Gewinnausschüttungen (vGA) und verdeckte Einlagen (vE) Vorschriften eingeführt, die eine korrespondierende Besteuerung der Kapitalgesellschaft und ihrer Anteilseigner gewährleisten sollen, sog. Korrespondenzprinzip. ${ }^{16}$ Das Korrespondenzprinzip bei der verdeckten Einlage sieht vor, dass das Einkommen der Kapitalgesellschaft zu erhöhen ist, soweit eine verdeckte Einlage das Einkommen des (den Vorteil gewährenden) Gesellschafters gemindert hat.

\subsubsection{Verdeckte Gewinnausschüttung}

Eine vGA i. S. des $§ 8$ Abs. 3 Satz 2 KStG ist ,eine Vermögensminderung oder verhinderte Vermögensmehrung, die durch das Gesellschaftsverhältnis veranlasst ist, sich auf die Höhe des Unterschiedsbetrags i. S. des $\S 4$ Abs. 1 Satz 1 EStG auswirkt und nicht auf einem den gesellschaftsrechtlichen Vorschriften entsprechenden Gewinnverteilungsbeschluss beruht“" ${ }^{17}$ Dementsprechend liegt eine verdeckte Gewinnausschüttung grundsätzlich dann vor, wenn der steuerliche Gewinn der Gesellschaft aufgrund des Gesellschaftsverhältnisses gemindert worden ist.

Im Gegensatz zu den Regelungen zur verdeckten Einlage ist die verdeckte Gewinnausschüttung auch auf Vorteilsgewährungen anwendbar, die keine einlagefähigen Wirtschaftsgüter umfassen. Die Frage, ob eine Vermögensminderung durch das Gesellschaftsverhältnis veranlasst ist, ist vor dem Hintergrund zu klären, ob ein ordentlicher und

\footnotetext{
${ }^{14}$ Vgl. § 8 Abs. 3 S. 3 KStG.

${ }^{15} \mathrm{Vgl}$. R 40 Abs. 4 KStR.

${ }^{16}$ Vgl. § 3 Nr. 40 Satz 1 Buchst. d) Sätze 2 und 3 EStG, § 8 Abs. 3 S. 3-6 KStG; § 8b Abs. 1 S. 2-4 KStG, Abs. 2 KStG.

${ }^{17} \mathrm{Vgl}$. R 36 KStR.
} 
gewissenhafter Geschäftsleiter diese Vermögensminderung bzw. verhinderte Vermögensmehrung akzeptiert hätte. Die verdeckte Gewinnausschüttung wird dementsprechend vor dem Hintergrund des ordentlichen und gewissenhaften Geschäftsleiters zum Fremdvergleichspreis bewertet und das Einkommen der ausschüttenden Gesellschaft entsprechend erhöht. ${ }^{18}$

Ebenso wie bei der verdeckten Einlage wurde bei der verdeckten Gewinnausschüttung das Korrespondenzprinzip eingeführt. ${ }^{19}$ Voraussetzung für die Steuerfreiheit (95\%) der verdeckten Gewinnausschüttung auf Seiten des Empfängers ist gem. $\S 8 \mathrm{~b}$ Abs. $1 \mathrm{KStG}$ seitdem, dass die verdeckte Gewinnausschüttung das Einkommen der ausschüttenden Gesellschaft erhöht bzw. nicht gemindert hat.

Bei der Anwendung der Regelungen zur verdeckten Gewinnausschüttung wird grundsätzlich bereits dann eine verdeckte Gewinnausschüttung angenommen, wenn es für Geschäftsbeziehungen zwischen der Gesellschaft und ihrem beherrschenden Gesellschafter an einer zivilrechtlich wirksamen, klaren, eindeutigen und im Voraus abgeschlossenen Vereinbarung darüber fehlt, ob und in welcher Höhe ein Entgelt für eine Leistung des Gesellschafters zu zahlen ist, oder wenn nicht einer klaren Vereinbarung entsprechend verfahren wird. ${ }^{20}$ Hierbei ist jedoch $\mathrm{zu}$ beachten, dass nach der Rechtsprechung ${ }^{21}$ Art. 9 OECD-MA eine Sperrwirkung dahingehend entfaltet, dass eine Einkommenskorrektur nur dann möglich ist, wenn die Gewinne eines Unternehmens aufgrund des Ansatzes nicht fremdüblicher Verrechnungspreise gemindert worden sind. Dementsprechend ist, solange die Verrechnungspreise dem Fremdvergleich entsprechen, eine Korrektur aufgrund formaler Mängel nicht möglich. Wird eine grenzüberschreitende konzerninterne Transaktion von der Betriebsprüfung allein aufgrund formaler Mängel aufgegriffen, sollte geprüft werden, ob ein Doppelbesteuerungsabkommen zwischen Deutschland und dem betreffenden Staat, gegenüber dem die verdeckte Gewinnausschüttung angenommen wurde, besteht. Wie vorstehend dargestellt, hat die Bundesrepublik Deutschland eine dem Art. 9 OECD-MA vergleichbare Regelung in seine jeweiligen Doppelbesteuerungsabkommen aufgenommen, so dass diese Regelung gegenüber der nationalen Regelung zur verdeckten Gewinnausschüttung Sperrwirkung entfaltet.

${ }^{18}$ Vgl. $§ 8$ Abs. 3 S. 2 KStG.

${ }^{19}$ Vgl. § 3 Nr. 40 Satz 1 Buchst. d) Sätze 2 und 3 EStG, § 8 Abs. 3 S. 3-6 KStG; § 8b Abs. 1 S. 2-4 $\mathrm{KStG}, \mathrm{Abs} .2 \mathrm{KStG}$.

${ }^{20}$ Vgl. R 36 Abs. 2 KStR.

${ }^{21}$ Vgl. FG Köln v. 22. August 2007 zum Doppelbesteuerungsabkommen mit Großbritannien und BFH v. 11.10.2012 zum Doppelbesteuerungsabkommen mit den Niederlanden. 


\subsection{4 §1 AStG}

\subsubsection{Tatbestandsmerkmale}

„Werden Einkünfte eines Steuerpflichtigen aus einer Geschäftsbeziehung zum Ausland mit einer ihm nahe stehenden Person dadurch gemindert, dass er seiner Einkünfteermittlung andere Bedingungen, insbesondere Preise (Verrechnungspreise), zugrunde legt, als sie voneinander unabhängige Dritte unter gleichen oder vergleichbaren Verhältnissen vereinbart hätten (Fremdvergleichsgrundsatz), sind seine Einkünfte unbeschadet anderer Vorschriften so anzusetzen, wie sie unter den zwischen voneinander unabhängigen Dritten vereinbarten Bedingungen angefallen wären". ${ }^{22}$ Seit der Änderung des $\S 1$ AStG in 2008 im Rahmen des Unternehmenssteuerreformgesetzes findet der $\S 1 \mathrm{AStG}$ auch dann ergänzend Anwendung, wenn eine Korrektur des § 1 AStG über andere Korrekturen hinausginge. Im Folgenden werden die neben der Minderung der Einkünfte weiteren Tatbestandsvoraussetzungen des $\S 1 \mathrm{AStG}$ und die damit zusammenhängenden Fragestellungen dargestellt.

Steuerpflichtiger Die Einkünfte eines Steuerpflichtigen müssen gemindert sein. Die Regelungen des $\S 1 \mathrm{AStG}$ finden unabhängig davon Anwendung, ob es sich hierbei um einen unbeschränkt Steuerpflichtigen oder um einen in Deutschland beschränkt Steuerpflichtigen handelt. Bis einschließlich 2012 unterlag eine Mitunternehmerschaft (Personengesellschaft) nicht den Regelungen des $§ 1$ AStG. Jedoch wurde die Anwendung des $\S 1$ AStG durch das AmtshilfeRLUmsG ab dem Veranlagungszeitraum 2013 ausgeweitet, seitdem gelten die Regelungen des $\S 1 \mathrm{AStG}$ auch für Personengesellschaften. Dies entspricht der bisherigen Rechtsauffassung der deutschen Finanzverwaltung. ${ }^{23}$

Geschäftsbeziehungen Eine Korrektur nach $\S 1 \mathrm{AStG}$ kann nur dann vorgenommen werden, wenn eine Geschäftsbeziehung vorliegt. Die Frage wann eine Geschäftsbeziehung vorliegt, ist Gegenstand einer umfangreichen Rechtsprechung. Nach Änderungen des $§ 1$ AStG zum Thema der Geschäftsbeziehung (zuletzt in 2012) ist eine Geschäftsbeziehung jeder:

einzelne oder mehrere zusammenhängende wirtschaftliche Vorgänge (Geschäftsvorfälle) zwischen einem Steuerpflichtigen und einer ihm nahestehenden Person,

a)

die Teil einer Tätigkeit des Steuerpflichtigen oder der nahestehenden Person sind, auf die die $\S \S 13,15,18$ oder 21 des Einkommensteuergesetzes anzuwenden sind oder anzuwenden wären, wenn sich der Geschäftsvorfall im Inland unter Beteiligung eines unbeschränkt Steuerpflichtigen und einer inländischen nahestehenden Person ereignet hätte, und

b)

denen keine gesellschaftsvertragliche Vereinbarung zugrunde liegt; eine gesellschaftsvertragliche Vereinbarung ist eine Vereinbarung, die unmittelbar zu einer rechtlichen Änderung der Gesellschafterstellung führt;

${ }^{22}$ Vgl. $§ 1$ Abs. 1 S. 1 AStG.

${ }^{23}$ Vgl. Anwendungsschreiben zum AStG v. 14.05.2004, Tz. 1.4.3. 
2. Geschäftsvorfälle zwischen einem Unternehmen eines Steuerpflichtigen und seiner in einem anderen Staat gelegenen Betriebsstätte (anzunehmende schuldrechtliche Beziehungen). Liegt einem Geschäftsvorfall keine schuldrechtliche Vereinbarung zugrunde, ist davon auszugehen, dass voneinander unabhängige ordentliche und gewissenhafte Geschäftsleiter eine schuldrechtliche Vereinbarung getroffen hätten oder eine bestehende Rechtsposition geltend machen würden, die der Besteuerung zugrunde zu legen ist, es sei denn, der Steuerpflichtige macht im Einzelfall etwas anderes glaubhaft.

Seit der Änderung der Definition der Geschäftsbeziehung in 2003 stellen auch zinslose Darlehen sowie die Vergabe von Garantien an verbundene Unternehmen grundsätzlich Geschäftsbeziehungen gem. § 1 AStG dar, selbst wenn diese eigenkapitalersetzenden Charakter haben. Auch Forderungsverzichte können grundsätzlich wirtschaftliche Beziehungen sein, die unter den Anwendungsbereich des $\S 1$ AStG fallen. Da die Frage, ob es sich um eine gesellschaftsrechtliche Beziehung oder einen wirtschaftlichen Vorgang handelt, essenziell für die Frage der Anwendbarkeit des $§ 1 \mathrm{AStG}$ ist, sollte bei Unklarheiten deutlich gemacht werden, dass es sich um eine gesellschaftsrechtliche Vereinbarung handelt, beispielsweise anhand des Gesellschaftervertrages, um eine weitergehende Anpassung gem. $§ 1 \mathrm{AStG}$ zu verhindern. ${ }^{24}$

Im Hinblick auf Beziehungen zwischen Stammhaus und Betriebsstätte ging die Finanzverwaltung stets von einer Anwendbarkeit des $\S 1 \mathrm{AStG}$ auch für Betriebsstätten aus. ${ }^{25}$ Durch die Umsetzung des „Authorized OECD Approaches“ in nationales Recht und die entsprechende Erweiterung des $\S 1$ AStG mit Wirkung ab dem 01. Januar 2013 sind Betriebsstätten wie selbständige Legaleinheiten zu behandeln, § 1 Abs. 4 S. 1 Nr. 2 AStG. Der Fremdvergleichsgrundsatz gilt somit gleichermaßen im Verhältnis zwischen Stammhaus und Betriebsstätten.

Ausland Das Einkommen des Steuerpflichtigen muss im Verhältnis zum Ausland gemindert worden sein. Reine Inlandssachverhalte werden dementsprechend nicht durch das AStG erfasst. Geschäftsbeziehungen mit in Deutschland tätigen Steuerausländern werden jedoch durch das AStG erfasst, sofern deren Einkünfte nicht der beschränkten Steuerpflicht gem. § 49 EStG unterliegen. Nach überwiegender Meinung in der Literatur fielen Geschäftsbeziehungen mit ausländischen Betriebsstätten sowie ausländischen Personengesellschaften bis zur Erweiterung des $§ 1 \mathrm{AStG}$ nicht unter den Anwendungsbereich.

Nahestehend Voraussetzung für die Anwendung von $\S 1$ AStG ist, dass die Einkünfte aufgrund von Geschäftsbeziehungen mit nahestehenden Personen gemindert worden sind. Eine Person wird als zu dem Steuerpflichtigen nahestehend angesehen, wenn sie an dem Steuerpflichtigen oder der Steuerpflichtige an ihr direkt oder indirekt $25 \%$ oder mehr der Anteile hält und somit wesentlich beteiligt ist. Dies gilt auch dann, wenn ein dritter Steuerpflichtiger an beiden Gesellschaften $\mathbf{2 5} \%$ oder mehr der Anteile hält. $\S 1$ AStG ist insofern also auch zwischen Schwestergesellschaften anwendbar.

${ }^{24}$ Für weitere Informationen auch mit Beispielen vgl. Vögele/Raab in Vögele/Borstell/Engler, Verrechnungspreise, Kapitel A Rz. 179 ff.

${ }^{25}$ Vgl. Anwendungsschreiben zum AStG v. 14.05.2004, Tz. 1.4.3. 
Darüber hinaus kann eine Person auch dann zu dem Steuerpflichtigen als nahestehend gelten, wenn sie einen beherrschenden Einfluss auf den Steuerpflichtigen ausübt, auch wenn sie weniger als $25 \%$ der Anteile an dem Steuerpflichtigen hält. Für die Annahme eines beherrschenden Einflusses ist nicht erforderlich, dass es sich hierbei um einen gesellschaftsrechtlichen Einfluss handelt, stattdessen sind auch andere Einflussmöglichkeiten denkbar. ${ }^{26}$

Zudem kann ein Nahestehen aufgrund von Einflussmöglichkeiten außerhalb der jeweiligen Geschäftsbeziehungen liegen oder aufgrund einer Interessenidentität, im Sinne eines Interesses an der Einkünfteerzielung des anderen, vorliegen.

\subsubsection{Spezielle Regelungen zur Bestimmung des Fremdvergleichspreises gem. § 1 AStG}

Basis des $\S 1$ AStG ist der Fremdvergleich und steht somit grundsätzlich im Einklang mit den internationalen Regelungen. Sollte das Einkommen eines Steuerpflichtigen aufgrund nicht fremdüblicher Verrechnungspreise gemindert worden sein, kann eine Einkommenskorrektur gem. $\S 1 \mathrm{AStG}$ erfolgen. $\S 1 \mathrm{AStG}$ enthält darüber hinaus spezielle Regelungen zur Bestimmung des Fremdvergleichspreises. Im Folgenden werden die wichtigsten Regelungen des $\S 1$ AStG zur Bestimmung des Fremdvergleichspreises dargestellt.

Maßstab des Fremdvergleichs ist das Handeln eines ordentlichen und gewissenhaften Geschäftsleiters. Dieser Grundsatz, der bereits bei der Einordnung, ob eine verdeckte Gewinnausschüttung besteht oder nicht, maßgebend ist, wird im Rahmen des AStGs dahingehend erweitert, dass auf den doppelten ordentlichen und gewissenhaften Geschäftsleiter (also auf Ebene der deutschen wie auch auf Ebene der ausländischen Gesellschaft) abgestellt wird. ${ }^{27}$ Zudem gilt auch eine fiktive Informationstransparenz innerhalb des Konzerns, $\S 1$ Abs. 1 S. 3 AStG. Für die Bestimmung des Fremdvergleichspreises wird insofern angenommen, dass die an der Geschäftsbeziehung beteiligten Personen über sämtliche für die Bepreisung der Geschäftsbeziehung relevanten Informationen verfügen (Annahme der Informationstransparenz). Die Annahme der Informationstransparenz ist jedoch grundsätzlich nicht mit dem Fremdvergleich vereinbar, da bei der Preisfindung zwischen fremden Dritten die Parteien in aller Regel über keine vollständigen Informationen hinsichtlich der Kalkulationsgrundlagen ihres Geschäftspartners verfügen. Nach Auffassung der Finanzverwaltung soll Informationstransparenz insbesondere im Fall des hypothetischen Fremdvergleichs unterstellt werden, Tz. 3.2 VWG-FVerl. Aber auch in diesem Fall ist nicht ersichtlich, weshalb eine Annahme getroffen werden sollte, die dem Fremdvergleichsgrundsatz widerspricht. Insofern ist die Regelung des hypothetischen Fremdvergleichs vor dem Hintergrund der Schrankenwirkung des Art. 9 OECD-MA restriktiv auszulegen. ${ }^{28}$

\footnotetext{
${ }^{26}$ Vgl. BFH v. 19.01.1994, BStB1. II 1994, 725.

27 Vgl. § 1 Abs. 1 S. 3 AStG.

${ }^{28}$ Vgl. Wassermeyer AStG Kommentar, § 1 AStG, Anm. V8.
} 
Die Ermittlung des Fremdvergleichspreises ist in $\S 1$ Abs. 3 AStG näher definiert. Die Standardmethoden (Preisvergleichsmethode, Wiederverkaufspreismethode, Kostenaufschlagsmethode) sind bevorzugt anzuwenden, wenn uneingeschränkt vergleichbare Fremdvergleichsdaten vorliegen. Sofern mehrere uneingeschränkt vergleichbare Fremdvergleichswerte vorliegen, ist eine Bandbreite zu ermitteln und jeder dieser Werte ist als fremdüblich anzusehen. Wenn keine uneingeschränkt vergleichbaren Fremdvergleichsdaten vorliegen, sind sachgerechte Verrechnungspreismethoden unter Anwendung eingeschränkt vergleichbarer Fremdvergleichsdaten (bspw. die Suche nach Vergleichsunternehmen aus Datenbanken) anzuwenden. In diesem Fall ist die Bandbreite der als fremdüblich anzusehenden Werte sachgerecht einzuengen. Es ist nicht definiert, auf welche Art die Bandbreite einzuengen ist. Die VWGV sehen grundsätzlich eine Einengung aufgrund von Plausibilitätsüberlegungen oder Kontrollrechnungen mittels verschiedener Verrechnungspreismethoden vor. ${ }^{29}$ Sollte eine Einengung der Bandbreiten mittels der vorstehend genannten Methoden nicht möglich sein, sehen die VWGV die Einengung der Bandbreite mittels Reduzierung der Bandbreite um die oberen bzw. unteren $25 \%$ vor (sog. interquartile Bandbreite der Datenpunkte (bzw. Beobachtungen). Zudem können auch andere mathematische Verfahren zur Bandbreiteneinengung Anwendung finden, wenn diese für den Einzelfall besser geeignet sind.

Der BFH hatte mit seinem Urteil vom 17.10.2001 ${ }^{30}$ entschieden, dass im Falle einer Einkommensanpassung der für den Steuerpflichtigen günstigste Wert innerhalb einer Bandbreite anzuwenden ist. Im Rahmen der Unternehmenssteuerreform 2008 wurde geregelt, dass der Median maßgeblich ist, wenn der vom Steuerpflichtigen für seine Einkünfteermittlung verwendete Wert außerhalb der Bandbreite bzw. außerhalb der eingeengten Bandbreite liegt, $\S 1$ Abs. 3 S. 4 AStG. Eine Anpassung auf den Median kann, abhängig von der jeweiligen Bandbreite, zu erheblich höheren Anpassungen und somit zu für den Steuerpflichtigen ungünstigeren steuerlichen Folgen führen als eine Anpassung auf den obersten oder untersten Wert einer Bandbreite fremdüblicher Verrechnungspreise. Dies gilt auch für die Ermittlung des Verrechnungspreises im Rahmen des im Folgenden dargestellten hypothetischen Fremdvergleichs und der Transferpaketbewertung im Rahmen von Funktionsverlagerungen.

Soweit weder uneingeschränkt noch eingeschränkt vergleichbare Fremdvergleichsdaten vorliegen, sieht $\S 1$ AStG die Anwendung des hypothetischen Fremdvergleichs vor. Hierzu hat der Steuerpflichtige auf Basis von Planrechnungen den Einigungsbereich zwischen den beteiligten Parteien zu bestimmen. Fälle, in denen weder uneingeschränkt noch eingeschränkt vergleichbare Fremdvergleichsdaten vorliegen, werden in der Mehrzahl Übertragungen immaterieller Wirtschaftsgüter sein. Zudem gilt dies auch für die Transferpaketbewertung bei Funktionsverlagerungen, Tz. 2.2.1.2 VWG-FVerl. Für den Fall, dass die Anwendung des hypothetischen Fremdvergleichs notwendig ist,

${ }^{29}$ Vgl. Tz. 3.4.12.5. VWGV.

${ }^{30} \mathrm{BFH}$, Urteil vom 17.10.2001- I R 103-00. Konzernverrechnungspreise als vGA einer Vertriebsgesellschaft. 
immaterielle Wirtschaftsgüter Gegenstand dieser Transaktion sind und die tatsächliche Geschäftsentwicklung von der prognostizierten Geschäftsentwicklung abweicht, kann die Finanzverwaltung innerhalb von zehn Jahren den Verrechnungspreis korrigieren, § 1 Abs. 3 S. 12 AStG. In diesem Fall wird widerlegbar vermutet, dass zum Zeitpunkt des Geschäftsabschlusses Unsicherheiten im Hinblick auf die Preisvereinbarung bestanden und unabhängige Dritte eine sachgerechte Anpassungsregelung vereinbart hätten, $\S 1 \mathrm{Abs} .3$ S. 11 AStG. Die Beweislast, diese Vermutung zu widerlegen, liegt beim Steuerpflichtigen. Dementsprechend ist in solchen Fällen zu prüfen, ob nicht bereits zum Zeitpunkt der Transaktion eine sachgerechte Anpassungsklausel vereinbart werden sollte und hierdurch der Anpassungszeitraum eingeschränkt werden könnte.

\subsubsection{Spezielle Regelungen zur Funktionsverlagerung gem. § 1 AStG}

Eine weitere Besonderheit des AStG stellen die Regelungen zur Funktionsverlagerung dar. Für den Fall, dass eine Funktion als Ganzes übertragen wird, ist, sofern keine Ausnahmetatbestände einschlägig sind, das übertragene Transferpaket als Ganzes zu bewerten. Ein Transferpaket ist hierbei als die Gesamtheit der mit der Funktion übertragenen Chancen und Risiken, den Wirtschaftsgütern und den sonstigen Vorteilen anzusehen. Die Regelungen zur Funktionsverlagerung gelten ebenfalls für Zeiträume ab dem Veranlagungszeitraum 2008, also für alle Wirtschaftsjahre, die im Kalenderjahr 2008 enden.

Der Begriff der Funktion ist in der FVerlV definiert. Die FVerlV definiert eine Funktion als eine „Geschäftstätigkeit, die aus einer Zusammenfassung gleichartiger betrieblicher Aufgaben besteht, die von bestimmten Stellen oder Abteilungen eines Unternehmens erledigt werden“ ( $§ 1$ Abs. 1 FVerlV). Sie ist ein organischer Teil eines Unternehmens, ohne dass ein Teilbetrieb im steuerlichen Sinn vorliegen muss. Eine Funktionsverlagerung liegt vor, wenn ein Unternehmen einem verbundenden Unternehmen Wirtschaftsgüter und sonstige Vorteile überträgt, die es dem anderen Unternehmen erlauben, diese Funktion auszuüben. ${ }^{31}$

Ausdrücklich keine Fälle von Funktionsverlagerungen liegen im Fall einer Funktionsverdoppelung vor. Eine Funktionsverdoppelung wird angenommen, ,wenn es trotz Vorliegens der übrigen Voraussetzungen des Absatzes 2 Satz 1 innerhalb von fünf Jahren nach Aufnahme der Funktion durch das nahe stehende Unternehmen zu keiner Einschränkung der Ausübung der betreffenden Funktion durch das in Abs. 2 Satz 1 zuerst genannte Unternehmen kommt" ( 1 Abs. 6 FVerlV). In Fällen der Funktionsverdoppelung liegt jedoch dann eine Funktionsverlagerung vor, wenn es innerhalb von 5 Jahren zu einer Einschränkung der Funktion beim übertragenden Unternehmen kommt. ${ }^{32}$ Eine Funktionsverlagerung liegt ebenfalls nicht vor, wenn ausschließlich Wirtschaftsgüter veräußert oder zur Nutzung überlassen werden oder wenn nur Dienstleistungen erbracht werden, es sei denn, diese Geschäftsvorfälle sind Teil einer Funktionsverlagerung. Entsprechendes gilt, wenn Personal im Konzern entsandt wird, ohne dass eine Funktion mit übergeht, oder wenn der

\footnotetext{
${ }^{31}$ Vgl. Rz. 19 VWG-FVerl.

${ }^{32}$ Vgl. § 1 Abs. 6 FVerlV.
} 
Vorgang zwischen voneinander unabhängigen Dritten nicht als Veräußerung oder Erwerb einer Funktion angesehen würde, $\S 1$ Abs. 7 FverlV. Dies gilt beispielsweise bei einer fristgerechten Kündigung von Verträgen oder dem Auslaufen der Vertragsbeziehungen. ${ }^{33}$ Jedoch ist zu beachten, dass auch in diesen Fällen andere zivilrechtliche oder steuerrechtliche Normen, die eine Entschädigung des abgebenden Unternehmens vorsehen, einschlägig sein können.

Wenn eine Funktionsverlagerung vorliegt, ist jedoch dann keine Versteuerung eines Transferpakets notwendig, sondern es können Einzelverrechnungspreise für die übertragenden Wirtschaftsgüter angesetzt werden, wenn die folgenden Voraussetzungen erfüllt sind: ${ }^{34}$

a. keine wesentlichen immateriellen Wirtschaftsgüter und Vorteile Gegenstand der Funktionsverlagerung waren

b. dass die Summe der angesetzten Einzelverrechnungspreise, gemessen an der Bewertung des Transferpakets als Ganzes, dem Fremdvergleichsgrundsatz entspricht

c. macht der Steuerpflichtige glaubhaft, dass zumindest ein wesentliches immaterielles Wirtschaftsgut Gegenstand der Funktionsverlagerung ist, und bezeichnet er es genau, sind Einzelverrechnungspreise für die Bestandteile des Transferpakets anzuerkennen.

Hierbei ist jedoch grundsätzlich zu beachten, dass zumindest in diesen Fällen auch eine Bewertung des Transferpakets vorzunehmen wäre, um darzustellen, dass die Summe der Einzelverrechnungspreise in Einklang mit der Bewertung des Transferpakets als Ganzes stünde bzw. ein wesentliches immaterielles Wirtschaftsgut Gegenstand der Funktionsverlagerung ist oder keine wesentlichen immateriellen Wirtschaftsgüter und Vorteile Gegenstand der Funktionsverlagerung waren.

Grundsätzlich gilt, dass die Finanzverwaltung die Regelungen zur Funktionsverlagerung sehr weitgehend anwenden möchte. So nimmt die Finanzverwaltung eine Funktionsverlagerung bereits dann an, wenn die Produktion bestimmter Produkte oder Produktgruppen verlagert wird. ${ }^{35}$ Dies kommt in den Verwaltungsgrundsätzen Funktionsverlagerung zum Ausdruck. Diese weitreichende Anwendung ist jedoch nicht in allen Fällen gesetzlich gedeckt. ${ }^{36}$ Abschließend kann die Frage, wie weit der Anwendungsbereich der Regelungen zur Funktionsverlagerung geht, nur gerichtlich beantwortet werden. Es ist damit zu rechnen, dass diese Fälle in den nächsten Jahren verstärkt vor Gericht gelöst werden müssen.

Bei den Regelungen zur Bewertung des Transferpakets stellt sich insbesondere die Frage, inwieweit diese Regelungen mit den Regelungen in anderen Ländern kompatibel sind. Zwar gibt es auch auf Ebene der OECD mit dem neuen Chapter IX der OECD-RL

\footnotetext{
${ }^{33}$ Vgl. Rz. 60 VWG-FVerl.

${ }^{34}$ Vgl. § 1 Abs. 3 S. 10 AStG.

${ }^{35}$ Vgl. Rz. 16 VwG-FVerl.

${ }^{36}$ Vgl. Schreiber in Kroppen, Handbuch Internationale Verrechnungspreise, FVerl, Anm. 40.
} 
zu „Business Restructurings“ Entwicklungen, die eine Tendenz zur Gesamtbetrachtung erkennen lassen. Jedoch sind die nationalen deutschen Regelungen bisher noch erheblich umfassender, als die Regelungen auf Ebene der OECD bzw. auf Ebene der meisten Mitgliedsstaaten. ${ }^{37}$ Insofern könnten diese Regelungen häufig dazu führen, dass Doppelbesteuerungen entstehen, weil ausländische Finanzverwaltungen einen korrespondierenden Betriebsausgabenabzug bzw. eine korrespondierende Aktivierung des Transferpakets nicht anerkennen.

\subsection{Internationale Verrechnungspreisregelungen}

Die Doppelbesteuerung als Hemmnis der wirtschaftlichen Entwicklung und dementsprechend ihre Vermeidung wird insbesondere im Rahmen internationaler Organisationen diskutiert. Auf Ebene der Europäischen Union ist das EU Joint Transfer Pricing Forum als beratende Instanz für die EU-Kommission tätig. Das EU Joint Transfer Pricing Forum besteht aus international anerkannten Verrechnungspreisexperten, die sowohl aus der Privatwirtschaft als auch aus den Finanzverwaltungen der Mitgliedsstaaten stammen. Ziel ist es, die europäischen Regelungen zu Verrechnungspreisen (beispielsweise hinsichtlich Regelungen zu Verständigungs- bzw. Vorabverständigungsverfahren und Dokumentationsvorschriften) zu harmonisieren.

Neben dem EU Joint Transfer Pricing Forum werden insbesondere auf Ebene der OECD Regelungen für internationale Verrechnungspreise entwickelt. Auch die durch die Bundesrepublik Deutschland abgeschlossenen bilateralen Abkommen zur Vermeidung der Doppelbesteuerung orientieren sich an dem Musterabkommen der OECD ${ }^{38}$, das als Vorlage für Doppelbesteuerungsabkommen zwischen den Staaten dienen soll. Jedoch weichen einzelne Doppelbesteuerungsabkommen teilweise signifikant von diesem Musterabkommen ab, da das OECD-MA nur einen Vorschlag darstellt und das jeweilige Doppelbesteuerungsabkommen das Ergebnis einer Verhandlungslösung der beteiligten Staaten ist. Zudem spiegeln die jeweiligen Doppelbesteuerungsabkommen auch den Stand der Entwicklung auf Ebene der OECD wider. Insofern sind ältere Doppelbesteuerungsabkommen nicht immer auf dem gleichen Stand der aktuellen OECD Regelungen bspw. bei den Regelungen zur Betriebsstättengewinnermittlung. Die Doppelbesteuerungsabkommen, die sich am UN-MA (z. B. das DBA zwischen der Bundesrepublik Deutschland und der Republik Indien) orientieren, beinhalten zudem regelmäßig Regelungen, welche die spezifische Situation der Entwicklungsländer berücksichtigen.

Zum OECD-MA wird auch ein Musterkommentar (OECD-MK) veröffentlicht, welcher der weiteren Auslegung dienen soll. ${ }^{39}$

\footnotetext{
${ }^{37}$ Vgl. Kroppen/Nientimp, IStR 2011, S. 650.

${ }^{38}$ Vgl. OECD (2014), Model Tax Convention on Income and on Capital.

${ }^{39}$ Vgl. OECD (2014), Model Tax Convention on Income and on Capital.
} 
Neben dem OECD-MA und dem OECD-MK existieren die OECD-RL. Die OECDRL wurden durch den Finanzausschuss der OECD entwickelt und am 13.07.1995 veröffentlicht. Seitdem wurden diese kontinuierlich erweitert und überarbeitet. Der aktuelle Stand der OECD-RL stammt aus Juli 2010. Aufgrund der aktuellen Entwicklungen im Rahmen der Base Erosion and Profit Shifting Initiative der OECD (BEPS) ${ }^{40}$ wurden bereits einige Kapitel der Richtlinien überarbeitet, eine Überarbeitung weiterer Kapitel steht an, siehe Abschn. 2.3.1.

Die OECD-RL stellen zwar kein nationales deutsches Recht dar, sie stellen jedoch den übereinstimmenden Willen der OECD-Mitgliedsstaaten zur Anwendung des Fremdvergleichsgrundsatzes dar. ${ }^{41}$ Dementsprechend beziehen sich auch nationale Finanzverwaltungen auf die OECD-RL (s. bspw. VWGV), in Großbritannien sind sie explizit Teil der gesetzlichen Regelung zur Fremdvergleichsbestimmung. ${ }^{42}$ Insofern werden die OECDRL auch von den nationalen Gerichten zur Auslegung des Fremdvergleichsgrundsatzes herangezogen..$^{43} \mathrm{Sie}$, ,sind deshalb Ausgangspunkt aller Überlegungen bei der Beurteilung von Verrechnungspreisen“. ${ }^{44}$

\subsubsection{Inhalt der OECD-RL}

Die OECD-RL in der aktuellen Fassung gliedern sich in die folgenden Kapitel, die zum Teil durch die jüngsten OECD-Papiere aus der BEPS-Initiative ergänzt bzw. angepasst werden:

\section{Kapitel I: Der Fremdvergleichsgrundsatz ${ }^{45}$}

Dieses Kapitel gibt einen Überblick über den Fremdvergleichsgrundsatz. Es wird neben der Bedeutung des Fremdvergleichsgrundsatzes insbesondere dargestellt, welche Sachverhaltsaspekte bei der Bestimmung des Fremdvergleichspreises mit einbezogen werden müssen. Zudem werden in diesem Kapitel auch allgemeingültige Grundsätze beschrieben, die auch für die folgenden spezielleren Kapitel Gültigkeit haben. Diese umfassen bspw. die Möglichkeit der Verwendung von Mehrjahresdaten für die Anwendung der

\footnotetext{
${ }^{40} \mathrm{Vgl}$. http://www.oecd.org/ctp/beps.htm.

${ }^{41}$ Vgl. Eigelshoven/Ebering in Kroppen, Handbuch Internationale Verrechnungspreise, Vorbemerkungen, Anm. 9.

${ }^{42} \mathrm{Vgl}$. Eigelshoven/Ebering in Kroppen, Handbuch Internationale Verrechnungspreise, OECDKap., Vorbemerkungen, Anm. 10.

${ }^{43}$ Vgl. bspw. BFH v. 17.10.2001.

${ }^{44} \mathrm{Vgl}$. Eigelshoven/Ebering in Kroppen, Handbuch Internationale Verrechnungspreise, OECDKap., Vorbemerkungen, Anm. 21.

${ }^{45}$ Für eine deutsche Übersetzung der OECD-Verrechnungspreisleitlinien s. bspw. Schreiber/Nientimp Verrechnungspreise, 6. Auflage 2015.
} 
Verrechnungspreisanalyse. Das entsprechende Kapitel wird durch die finalen BEPS-Papiere zu den Action Items 8-10 abgeändert bzw. ergänzt. ${ }^{46}$

\section{Kapitel II: Verrechnungspreismethoden}

Dieses Kapitel stellt die einzelnen Verrechnungspreismethoden dar. Es werden sowohl die sogenannten Standardmethoden (Preisvergleichsmethode, Wiederverkaufspreismethode, Kostenaufschlagsmethode) als auch die gewinnorientierten Methoden innerhalb dieses Kapitels behandelt und ihre jeweilige Anwendung diskutiert (vgl. hierzu auch Kap. 5 Verrechnungspreismethoden und Ökonomische Analyse). Das entsprechende Kapitel wird durch die finalen BEPS-Papiere zu den Action Items 8-10 abgeändert bzw. ergänzt. ${ }^{47}$

\section{Kapitel III: Vergleichbarkeitsanalyse}

Grundsätzlich wird in Kap. I dargestellt, welche Sachverhaltsaspekte bei der Prüfung des Fremdvergleichs besonders zu berücksichtigen sind. Auch um die Wichtigkeit des Themas Vergleichbarkeitsanalyse herauszustreichen, hat die OECD bei der Überarbeitung der OECD-RL dem Thema Vergleichbarkeitsanalyse ein eigenes Kapitel gewidmet. Insbesondere findet sich in diesem Kapitel auch eine Auflistung der einzelnen Schritte, die bei der Vergleichbarkeitsanalyse zu berücksichtigen sind.

\section{Kapitel IV: Ansätze der Verwaltungen zur Vermeidung und Beilegung von Verrech- nungspreiskonflikten}

Dieses Kapitel befasst sich mit den Grundsätzen, die die jeweiligen Finanzverwaltungen bei der Prüfung von Verrechnungspreisen befolgen sollten. Dies umfasst beispielsweise Themen zur Beweislast und die Frage, wie weit nationale Mitwirkungspflichten des Steuerpflichtigen seitens der nationalen Finanzverwaltungen ausgelegt werden sollten. Weiterhin werden in diesem Kapitel unter anderem auch Grundsätze für die Finanzverwaltung für die Durchführung bilateraler Verständigungsverfahren und Vorabverständigungsverfahren (sog. Advance Pricing Agreements-APAs) diskutiert.

\section{Kapitel V: Dokumentation}

In Kap. V der OECD-RL wird erörtert, welche Nachweise die Finanzverwaltungen von den Steuerpflichtigen anfordern können. Hierbei wird insbesondere auch dargestellt, dass keine Informationen von den Steuerpflichtigen verlangt werden können, die objektiv betrachtet nicht vorliegen können. Es wird aber auch dargestellt, welche Informationen grundsätzlich für die Ermittlung des Fremdvergleichs nützlich sein könnten. Diese Informationen finden sich überwiegend auch in den deutschen Dokumentationsvorschriften wieder (vgl. GAufzV, siehe auch Kap. 3 Erstellung einer Verrechnungspreisdokumentation). Das

${ }^{46}$ Vgl. OECD (2015), Aligning Transfer Pricing Outcomes with Value Creation, Actions 8-10, S. $13-50$.

${ }^{47}$ Vgl. OECD (2015), Aligning Transfer Pricing Outcomes with Value Creation, Actions 8-10, S. 51-61. 
entsprechende Kapitel wird durch die finalen BEPS-Papiere zu Action Item 13 hinsichtlich des neuen OECD Dokumentationsansatzes vollständig ersetzt. ${ }^{48}$

\section{Kapitel VI: Besondere Überlegungen für immaterielle Wirtschaftsgüter}

Aufgrund der Besonderheiten der Verrechnungspreisermittlung bei immateriellen Wirtschaftsgütern sind die jeweiligen Überlegungen in Kap. VI kodifiziert. Dieses Kapitel war im Zuge des Updates der OECD-RL nicht Gegenstand der Überarbeitung. Das Kapitel wurde im Rahmen des BEPS-Projekts vollständig überarbeitet und wird durch die Anpassungen der Action Items $8-10$ ersetzt. $^{49}$

\section{Kapitel VII: Besondere Überlegungen zu konzerninternen Dienstleistungen}

Dieses Kapitel diskutiert besondere Themen bei der Bestimmung von Verrechnungspreisen für konzerninterne Dienstleistungen. Insbesondere wird in diesem Kapitel auch diskutiert, welche Dienstleistungen grundsätzlich verrechenbar sind und bei welchen Tätigkeiten es sich um gesellschafterbezogene Leistungen (sog. Shareholder bzw. Stewardship expenses) handelt und diese deshalb nicht verrechenbar sind. Das Kapitel wird durch die Ausführungen zu „Low Value Adding Services“ im BEPS-Papier zu den Action Items $8-10$ angepasst. ${ }^{50}$

\section{Kapitel VIII: Kostenumlagevereinbarung}

Dieses Kapitel beinhaltet grundlegende Überlegungen zu Kostenumlagevereinbarungen. Diese Überlegungen befassen sich auch mit der Frage, wie das wirtschaftliche Eigentum an den während der Laufzeit der Kostenumlagevereinbarung geschaffenen Wirtschaftsgütern aufgeteilt werden sollte und in welchen Fällen Eintrittszahlungen für neu eintretende Gesellschaften oder Abstandszahlungen für ausscheidende Gesellschaften sachgerecht sein könnten. Das Kapitel wird durch die Ausführungen zu Cost Contribution Arrangements im OECD-Papier zu den Action Items 8-10 entsprechend angepasst. ${ }^{51}$

\section{Kapitel IX: Verrechnungspreisaspekte bei Umstrukturierungen der Geschäftstätig- keit}

Dieses Kapitel wurde mit dem Update 2010 neu in die OECD-RL aufgenommen. Hiermit berücksichtigt die OECD die im Zuge der Globalisierung immer vordringlichere Frage, wie konzerninterne Umstrukturierungen bepreist werden könnten/müssten. Hierbei ist zu

${ }^{48}$ Vgl. OECD (2015), Transfer Pricing Documentation and Country-by-Country Reporting, Action 13.

${ }^{49}$ Vgl. OECD (2015), Aligning Transfer Pricing Outcomes with Value Creation, Actions 8-10, S. $63-140$.

${ }^{50}$ Vgl. OECD (2015), Aligning Transfer Pricing Outcomes with Value Creation, Actions 8-10, S. 141-160.

${ }^{51}$ Vgl. OECD (2015), Aligning Transfer Pricing Outcomes with Value Creation, Actions 8-10, S. 161-181. 
beachten, dass dieses Kapitel auch Sachverhalte diskutiert, die in Deutschland unter die Regelungen zur Funktionsverlagerung fallen. Grundsätzlich gilt jedoch, dass die deutschen Regelungen zur Funktionsverlagerung weitergehend sind, als die Regelungen in Kap. IX der OECD-RL. Im folgenden Abschnitt wird auf die Änderungen durch das BEPS-Projekt der OECD eingegangen.

\subsubsection{OECD - BEPS Maßnahmen}

Die OECD hat am 5. Oktober 2015 ihren Abschlussbericht zu den 15 BEPS Maßnahmen veröffentlicht. ${ }^{52}$ Die Relevanz des BEPS Action Plans hat die OECD mit Zahlen untermauert: laut den Ergebnissen einer Analyse geht die OECD davon aus, dass jährlich ca. 4-10\% der Körperschaftssteuereinnahmen durch BEPS-Aktivitäten von Unternehmen entfallen. Dies entspricht ca. US\$100-240 Mrd.53 Eine Übersicht über alle Maßnahmen des BEPS Action Plan findet sich im Folgenden:

Tab. 2.1 Übersicht OECD BEPS Maßnahmen

\begin{tabular}{l|l|l}
\hline Maßnahme & Titel & Inhalt \\
\hline Nr. 1 & Lösung der mit der digita- & Anhand von Analysen der verschiedenen \\
& len Wirtschaft verbundenen & Geschäftsmodelle auf dem Sektor der digita- \\
& Besteuerungsprobleme & len Wirtschaft soll die wirksame Erhebung von \\
& Mehrwertsteuer/Waren- und Dienstleistungsteuer \\
& im Zusammenhang mit der grenzüberschreitenden \\
& Lieferung bzw. Erbringung digitaler Waren und \\
& Dienstleistungen sichergestellt werden. Möglich- \\
& keiten der Unternehmen, durch ihre erhebliche \\
& digitale Präsenz wirtschaftliche Tätigkeiten in \\
& einem Land zu entfalten ohne aufgrund der aktu- \\
& ellen international vorhandenen Regelungen nicht \\
& steuerpflichtig zu sein, sollen eingeschränkt wer- \\
& den. In ihrem finalen Bericht schlägt die OECD \\
& vor, die Probleme der Besteuerung der digitalen \\
& Wirtschaft im Rahmen der anderen BEPS-Maß- \\
& nahmen zu lösen. Das Thema soll weiter beobach- \\
& tet und ggf. weiter bearbeitet werden. \\
\hline
\end{tabular}

${ }^{52} \mathrm{~S}$. http://www.oecd.org/ctp/beps.htm.

${ }^{53}$ Vgl. OECD Webcast Unterlagen 5. Oktober 2015, „Launch of the final BEPS Reports“, S. 51. 


\begin{tabular}{|c|c|c|}
\hline Maßnahme & Titel & Inhalt \\
\hline Nr. 2 & $\begin{array}{l}\text { Neutralisierung der } \\
\text { Effekte aus unterschiedli- } \\
\text { cher Einordnung hybrider } \\
\text { Gestaltungen }\end{array}$ & $\begin{array}{l}\text { Die durch unterschiedliche Einordung hybrider } \\
\text { Gestaltungen drohende doppelte Nichtbesteuerung } \\
\text { soll im Hinblick auf ihre schädliche Wirkung für } \\
\text { Wettbewerb, wirtschaftliche Effizienz, Transpa- } \\
\text { renz und Gerechtigkeit unterbunden werden. Zur } \\
\text { Vermeidung missbräuchlicher Inanspruchnahme } \\
\text { von abkommensrechtlichen Vorteilen kommt } \\
\text { eine Änderung des OECD-Musterabkommens } \\
\text { in Betracht. Ferner sind Anpassungen nationaler } \\
\text { Vorschriften zur Verhinderung von Befreiung } \\
\text { oder Nichtberücksichtigung von Zahlungen und } \\
\text { Ausschluss der Abzugsfähigkeit von Zahlungen, } \\
\text { die keinen Einkünften des Empfängers zurechen- } \\
\text { bar sind oder in anderen Staaten abziehbar sind, } \\
\text { anzudenken. In Betracht kommt der Aufbau von } \\
\text { Koordinierungs- und Kollisionsregeln zwischen } \\
\text { innerstaatlichen und OECD-Regeln. Die Behand- } \\
\text { lung von Einkommen im Rahmen der Hinzu- } \\
\text { rechnungsbesteuerung ist zu berücksichtigen. } \\
\text { Der finale OECD Bericht enthält Regelungen zur } \\
\text { Behandlung von Anleihen (,Stock Loans“) und } \\
\text { Rückkaufvereinbarungen (,,Repos“). }\end{array}$ \\
\hline Nr. 3 & $\begin{array}{l}\text { Stärkung der Vorschriften } \\
\text { zur Hinzurechnungsbesteu- } \\
\text { erung (sog. CFC-Rules) }\end{array}$ & $\begin{array}{l}\text { Empfehlungen zur Gestaltung von Vorschriften zur } \\
\text { Hinzurechnungsbesteuerung, um zu verhindern, } \\
\text { dass Gesellschaften bei verbundenen Unterneh- } \\
\text { men, die von einer niedrigen Besteuerung profitie- } \\
\text { ren, Zinsaufwendungen geltend machen, während } \\
\text { die beim Kreditgeber anfallenden Zinserträge } \\
\text { nicht gleichermaßen berücksichtigt werden. }\end{array}$ \\
\hline Nr. 4 & $\begin{array}{l}\text { Begrenzung der Erosion } \\
\text { der Besteuerungsgrundlage } \\
\text { durch Abzug von Zins- } \\
\text { oder sonstigen finanziellen } \\
\text { Aufwendungen }\end{array}$ & $\begin{array}{l}\text { Zur Unterstützung der vorangegangen Maßnah- } \\
\text { men hat die OECD einen Leitfaden zu Ver- } \\
\text { rechnungspreisen bei Finanztransaktionen mit } \\
\text { nahestehenden Parteien erarbeitet. Der Nettozin- } \\
\text { saufwand soll bis zu einer bestimmten Grenze } \\
\text { (10\% bis } 30 \%) \text { des EBITDA (bei der in Deutsch- } \\
\text { land geltenden Zinsscharanke liegt die Grenze bei } \\
30 \% \text { des sog. ,,verrechenbaren EBITDA“). Eine } \\
\text { Ausnahme soll für einzelne Teile eines Konzerns } \\
\text { mit hohem Verschuldungsgrad gelten. Weitere } \\
\text { Aspekte wie der Umgang mit Banken und Versi- } \\
\text { cherungen sollen im Laufe der Jahre 2016/2017 } \\
\text { separat bearbeitet werden. }\end{array}$ \\
\hline
\end{tabular}




\begin{tabular}{|c|c|c|}
\hline Maßnahme & Titel & Inhalt \\
\hline \multirow[t]{4}{*}{ Nr. 5} & \multirow[t]{4}{*}{$\begin{array}{l}\text { Wirksamere Bekämpfung } \\
\text { steuerschädlicher Praktiken } \\
\text { unter Berücksichtigung von } \\
\text { Transparenz und Substanz }\end{array}$} & $\begin{array}{l}\text { Zur Verbesserung der Transparenz sollen Informa- } \\
\text { tionen zu Präferenzsystemen ausgetauscht werden, } \\
\text { sowie die Bedingung gelten, dass zur Anwendung } \\
\text { solcher Systeme eine substantielle Tätigkeit gege- } \\
\text { ben sein muss. }\end{array}$ \\
\hline & & $\begin{array}{l}\text { Im finalen Bericht sieht die OECD die Anwen- } \\
\text { dung eines modifizierten Nexus-Ansatzes vor: der } \\
\text { Umfang der Begünstigung richtet sich danach, in } \\
\text { welchem Verhältnis die qualifizierten Ausgaben } \\
\text { des Steuerpflichtigen für die Entwicklung und } \\
\text { Verwertung von IP zu den Gesamtausgaben für } \\
\text { diese Tätigkeiten stehen. Ausgaben für Auftrags- } \\
\text { forschung oder die Anschaffung durch verbundene } \\
\text { Unternehmen können teilweise (zu bis zu } 30 \% \text { der } \\
\text { Gesamtforschungsausgaben) „qualifizierten Aus- } \\
\text { gaben“ darstellen. }\end{array}$ \\
\hline & & $\begin{array}{l}\text { Das begünstigte IP wird auf drei Kategorien } \\
\text { beschränkt: Patente, copyright-geschützte Soft- } \\
\text { ware sowie ähnliche Wirtschaftsgüter (Trademarks } \\
\text { und Marketing-IP sind nicht erfasst). }\end{array}$ \\
\hline & & $\begin{array}{l}\text { Der finale OECD-Bericht enthält zudem Rege- } \\
\text { lungen zur Verhinderung der Verlagerung von IP } \\
\text { zwischen verbundenen Unternehmen nach dem } \\
01.01 .2016 \text {. }\end{array}$ \\
\hline Nr. 6 & $\begin{array}{l}\text { Verhinderung von } \\
\text { Abkommensmissbrauch }\end{array}$ & $\begin{array}{l}\text { OECD-Regelwerk und innerstaatliche Vorschrif- } \\
\text { ten sind so anzupassen, dass Abkommensvorteile } \\
\text { nicht in unangemessenen Fällen gewährt werden. } \\
\text { Eine doppelte Nichtbesteuerung gilt es zu ver- } \\
\text { hindern. Eine Koordination mit der Maßnahme } \\
\text { zu hybriden Gestaltungen (Maßnahme Nr. 2) soll } \\
\text { erfolgen. }\end{array}$ \\
\hline
\end{tabular}




\begin{tabular}{|c|c|c|}
\hline Maßnahme & Titel & Inhalt \\
\hline \multirow[t]{4}{*}{ Nr. 7} & \multirow[t]{4}{*}{$\begin{array}{l}\text { Verhinderung der künstli- } \\
\text { chen Umgehung des Status } \\
\text { als Betriebsstätte }\end{array}$} & $\begin{array}{l}\text { Ziel der OECD-BEPS Maßnahme } 7 \text { ist es, künstli- } \\
\text { chen Komissionärsstrukturen Einhalt zu gebieten. } \\
\text { Nach der geplanten Neufassung der Art. } 5 \text { Abs. } 5 \\
\text { OECD-MA soll eine Betriebsstätte dann begründet } \\
\text { werden, wenn eine Person die Vollmacht besitzt } \\
\text { für ein Unternehmen Verträge abzuschließen oder } \\
\text { gewöhnlich die wesentliche Rolle beim Vertrags- } \\
\text { abschluss übernimmt, die dann regelmäßig ohne } \\
\text { substanzielle Änderungen vom Unternehmen } \\
\text { abgeschlossen werden. }\end{array}$ \\
\hline & & $\begin{array}{l}\text { Anstelle der bisherigen Fokussierung auf eine } \\
\text { formelle Abschlussvollmacht ist nunmehr ent- } \\
\text { scheidend, wer wirtschaftlich betrachtet in den } \\
\text { Vertragsabschluss eingebunden ist. }\end{array}$ \\
\hline & & $\begin{array}{l}\text { Zudem wurde das Kriterium der sog. Vorbereiten- } \\
\text { den oder Hilfstätigkeiten ausgeweitet. Der Katalog } \\
\text { an vorbereitenden und Hilfstätigkeiten soll bei } \\
\text { Vorliegen nur dann keine Betriebsstätte begrün- } \\
\text { den, wenn es sich insgesamt um eine vorberei- } \\
\text { tende oder Hilfstätigkeit handelt. }\end{array}$ \\
\hline & & $\begin{array}{l}\text { Des Weiteren wurde eine Antifragmentierungs- } \\
\text { regelung eingeführt. Der Ausnahmetatbestand } \\
\text { der vorbereitenden oder Hilfstätigkeit findet dann } \\
\text { keine Anwendung, wenn das Unternehmen in dem } \\
\text { betreffenden Vertragsstaat bereits Geschäftstätig- } \\
\text { keiten ausübt, die eine Betriebsstätte begründen } \\
\text { oder die aus der Kombination der Tätigkeiten } \\
\text { resultierende Gesamttätigkeit keine vorbereitende } \\
\text { oder Hilfstätigkeit ist. Die Möglichkeit, eine } \\
\text { Betriebsstätte zu vermeiden, indem Aktivitäten in } \\
\text { mehrere vorbereitende oder Hilfstätigkeiten auf- } \\
\text { geteilt werden, besteht somit nicht mehr. }\end{array}$ \\
\hline
\end{tabular}




\begin{tabular}{|c|c|c|}
\hline Maßnahme & Titel & Inhalt \\
\hline \multirow[t]{2}{*}{ Nr. $8-10$} & \multirow[t]{2}{*}{$\begin{array}{l}\text { Immaterielle } \\
\text { Wirtschaftsgüter }\end{array}$} & $\begin{array}{l}\text { Als Teil der Ergebnisse der BEPS-Maßnahmen } \\
8-10 \text { hat die OECD am 5. Oktober } 2015 \text { die finale } \\
\text { Fassung der Richtlinien zu immateriellen Wirt- } \\
\text { schaftsgütern veröffentlicht und ersetzt damit die } \\
\text { bisher geltenden Regelungen des Kapitels VI der } \\
\text { OECD-Verrechnungspreisrichtlinien. Neben über- } \\
\text { arbeiteten Vorgaben zur Definition und Abgren- } \\
\text { zung des Begriffs ,immaterielles Wirtschaftsgut“, } \\
\text { ausführlichen Vorgaben zur Zuordnung von Erträ- } \\
\text { gen auf Basis der für die Wertschöpfung relevan- } \\
\text { ten Funktionen und Neuerungen zur Behandlung } \\
\text { von Ex-post-Abweichungen macht die OECD } \\
\text { auch besondere Vorgaben in Bezug auf schwer } \\
\text { zu bewertende immaterielle Wirtschaftsgüter. Die } \\
\text { Neuerungen zielen - wie alle anderen verrech- } \\
\text { nungspreisrelevanten BEPS-Maß-nahmen - ins- } \\
\text { besondere darauf ab, Gewinne im Einklang mit } \\
\text { Wertschöpfung und Substanz zuzuordnen. Als } \\
\text { Folge zeigt sich, dass die Durchführung einer } \\
\text { umfassenden, präzisen Funktions- und Risikoana- } \\
\text { lyse und entsprechender Gewinnzuordnung weiter } \\
\text { an Bedeutung gewinnen wird. }\end{array}$ \\
\hline & & $\begin{array}{l}\text { Traditionelle einseitige Verrechnungspreismetho- } \\
\text { den treten gegenüber zweiseitigen Methoden und } \\
\text { Bewertungsmethoden stärker in den Hintergrund. } \\
\text { Im Hinblick auf schwer zu bewertende imma- } \\
\text { terielle Wirtschaftsgüter hat die OECD etliche } \\
\text { Neuerungen formuliert. Da die Vorhersage von } \\
\text { Finanzdaten und der Nachweis, was vorhersehbar } \\
\text { und nicht vorhersehbar ist, in der Praxis in vielen } \\
\text { Fällen schwierig sein wird, ist damit zu rechnen, } \\
\text { dass Steuer-behörden in Zukunft vermehrt die } \\
\text { Überprüfung anhand von Ex-post-Informationen } \\
\text { vornehmen und Verrechnungspreise anpassen } \\
\text { werden. }\end{array}$ \\
\hline
\end{tabular}




\begin{tabular}{|c|c|c|}
\hline Maßnahme & Titel & Inhalt \\
\hline \multirow[t]{2}{*}{ Nr. 8} & \multirow[t]{2}{*}{ Kostenumlageverträge } & $\begin{array}{l}\text { Als Teil der Ergebnisse der BEPS-Maßnahme } 8 \\
\text { hat die OECD die finale Fassung der Richtlinien } \\
\text { zu Cost Contribution Arrangements (CCA) ver- } \\
\text { öffentlicht und ersetzt damit die bisher geltenden } \\
\text { Regelungen des Kapitels VIII der OECD-Richt- } \\
\text { linien. Die wesentlichen Änderungen betreffen die } \\
\text { Bestimmung der Teilnehmer eines CCA und die } \\
\text { Messung der Beiträge zu einem CCA. }\end{array}$ \\
\hline & & $\begin{array}{l}\text { Fundamentale Änderungen stellen die Bedingung, } \\
\text { dass jeder Teilnehmer Kontrolle über die jeweils } \\
\text { mit dem CCA verbundenen Risiken haben muss, } \\
\text { und die Vorgabe, dass die Beiträge zu einem } \\
\text { CCA in der Regel mit dem jeweiligen Wertbei- } \\
\text { trag gemessen werden anstatt mit den Kosten, im } \\
\text { Vergleich zum bisherigen CCA-Konzept dar. Die } \\
\text { Anwendung einer konsequent durchgeführten } \\
\text { Funktions- und Risikoanalyse der an einem CCA } \\
\text { teilnehmenden Unternehmen ist zu diesem Zweck } \\
\text { unabdingbar. }\end{array}$ \\
\hline \multirow[t]{5}{*}{ Nr. 9} & \multirow[t]{5}{*}{ Risiko und Kapital } & $\begin{array}{l}\text { Kern des Aktionspunkts } 9 \text { ist die Vermeidung von } \\
\text { BEPS durch die Übertragung von Risiken zwi- } \\
\text { schen Gruppenmitgliedern oder die übermäßige } \\
\text { Kapitalausstattung einzelner Gruppenmitglieder. } \\
\text { Des Weiteren soll BEPS durch strukturell fremd- } \\
\text { unübliche Transaktionen verhindert werden. }\end{array}$ \\
\hline & & $\begin{array}{l}\text { Die OECD möchte sicherstellen, dass die tatsäch- } \\
\text { lichen Geschäftsbeziehungen zwischen verbunde- } \\
\text { nen Unternehmen sauber identifiziert werden und } \\
\text { Verrechnungspreise zukünftig nicht auf vertrag- } \\
\text { lichen Vereinbarungen basieren, die die ökonomi- } \\
\text { sche Realität nicht widerspiegeln. }\end{array}$ \\
\hline & & $\begin{array}{l}\text { Kapitalgeber, die keine Kontrolle über das Inves- } \\
\text { titionsrisiko haben und auch sonst keine mit dem } \\
\text { Kapital verbundenen Funktion erfüllen, die eine } \\
\text { Risikoprämie rechtfertigen würde, sollen nicht } \\
\text { mehr als einen risikofreien Beitrag erwarten. }\end{array}$ \\
\hline & & $\begin{array}{l}\text { Zukünftig soll es Steuerbehörden erlaubt sein, } \\
\text { Transaktionen zwischen verbundenen Unter- } \\
\text { nehmen dann nicht anzuerkennen, wenn sie als } \\
\text { ökonomisch irrational eingestuft werden. }\end{array}$ \\
\hline & & $\begin{array}{l}\text { In Zukunft müssen Risiken bzw. Risikoallo- } \\
\text { kationen genau und umfangreich beschrieben, } \\
\text { analysiert und dokumentiert werden. Die OECD } \\
\text { vertritt die Sichtweise, dass demjenigen das Risiko } \\
\text { zuzuordnen ist, der die Kontrolle über das Risiko } \\
\text { und die finanziellen Mittel hat, um dieses Risiko } \\
\text { zu tragen. }\end{array}$ \\
\hline
\end{tabular}




\begin{tabular}{|c|c|c|}
\hline Maßnahme & Titel & Inhalt \\
\hline \multirow[t]{3}{*}{ Nr. 10} & \multirow[t]{3}{*}{ Gewinnaufteilungsmethode } & $\begin{array}{l}\text { Die OECD hat weitere Ankündigungen zu geplan- } \\
\text { ten Änderungen der Richtlinien für die Anwen- } \\
\text { dung der Profit-Split-Methode (PSM) gemacht. } \\
\text { Im Gegensatz zu den anderen verrechnungspreis- } \\
\text { relevanten BEPS-Maßnahmen stellt dieser Teil } \\
\text { der Veröffentlichung keine finalen Ergebnisse vor, } \\
\text { sondern gibt lediglich eine Zusammenfassung } \\
\text { des Diskussionsstands und einen Ausblick auf } \\
\text { die wesentlichen Punkte der noch ausstehenden } \\
\text { Überarbeitungen. Die Ergebnisse werden somit } \\
\text { zum derzeitigen Zeitpunkt zu keinen konkreten } \\
\text { Anpassungen der OECD-Verrechnungspreisricht- } \\
\text { linien führen. }\end{array}$ \\
\hline & & $\begin{array}{l}\text { Die überarbeitete Richtlinie zur Anwendung der } \\
\text { transaktionsbezogenen PSM soll klarstellen, } \\
\text { unter welchen Bedingungen diese Methode die } \\
\text { angemessenste Methode ist, und Ansätze beschrei- } \\
\text { ben, mit denen Gewinne auf eine verlässliche Art } \\
\text { und Weise aufgeteilt werden können. Um dies } \\
\text { zu erreichen, will die OECD insbesondere auch } \\
\text { die Ergebnisse der anderen BEPS-Maßnahmen } \\
\text { berücksichtigen, wodurch die Durchführung einer } \\
\text { umfassenden, präzisen Funktions- und Risikoana- } \\
\text { lyse weiter an Bedeutung gewinnen wird. }\end{array}$ \\
\hline & & $\begin{array}{l}\text { Als Zeitplan hat die OECD angekündigt, einen } \\
\text { Diskussionsentwurf in der ersten Hälfte des Jahres } \\
2016 \text { zu veröffentlichen und eine öffentliche } \\
\text { Konsultation hierzu im Mai } 2016 \text { abzuhalten. Die } \\
\text { Finalisierung der Richtlinie ist für die erste Hälfte } \\
\text { des Jahres } 2017 \text { angesetzt. }\end{array}$ \\
\hline
\end{tabular}




\begin{tabular}{|c|c|c|}
\hline Maßnahme & Titel & Inhalt \\
\hline \multirow[t]{2}{*}{ Nr. 10} & \multirow[t]{2}{*}{$\begin{array}{l}\text { Dienstleistungen mit } \\
\text { geringer Wertschöpfung }\end{array}$} & $\begin{array}{l}\text { Der finale OECD Bericht enthält als maßgebliche } \\
\text { Neuerung zu den bisherigen OECD-Richtlinien } \\
\text { Ausführungen zu einem optionalen vereinfachten } \\
\text { Ansatz zur Bestimmung von Verrechnungspreisen } \\
\text { für konzerninterne Dienstleistungen mit geringem } \\
\text { Wertschöpfungsbeitrag. Ziel ist es, dazu beizutra- } \\
\text { gen, ein Gleichgewicht zwischen einer angemesse- } \\
\text { nen Vergütung für solche Dienstleistungen und der } \\
\text { Sicherung von Besteuerungssubstrat in den dienst- } \\
\text { leistungsempfangenden Staaten zu erreichen. }\end{array}$ \\
\hline & & $\begin{array}{l}\text { Zu diesem Zweck enthält der OECD Bericht einen } \\
\text { Katalog von Dienstleistungen mit geringer Wert- } \\
\text { schöpfung. Bei der konzerninternen Verrechnung } \\
\text { soll ein einheitlicher Aufschlag von 5\% auf die } \\
\text { entstandenen Kosten herangezogen werden. Der } \\
\text { Aufwand der Nutzendokumentation (sog. Benefit } \\
\text { Test) für den Leistungsempfänger soll auf ein } \\
\text { vernünftiges Maß reduziert werden, sodass bei } \\
\text { Erfüllung der vorgesehenen Dokumentations-an- } \\
\text { forderungen eine jährliche Rechnung genügen } \\
\text { würde, aus der die Beschreibung der Dienstleis- } \\
\text { tungskategorien hervorgeht. }\end{array}$ \\
\hline Nr. 10 & $\begin{array}{l}\text { Warentransaktionen mit } \\
\text { öffentlicher Preissetzung }\end{array}$ & $\begin{array}{l}\text { Im Rahmen des BEPS-Aktionspunkts } 10 \\
\text { (Ergänzung des Kapitels II der OECD-Verrech- } \\
\text { nungspreisrichtlinien) wurde zudem die Preis- } \\
\text { vergleichsmethode als vorrangig anzuwendende } \\
\text { Methode unter Heran-ziehung eines notierten } \\
\text { Preises als Vergleichspreis für Warentransaktionen } \\
\text { mit öffentlicher Preisfestsetzung (,,commodity } \\
\text { transactions“) festgelegt. Gegenüber dem ersten } \\
\text { Diskussionsentwurf wurden insbesondere die } \\
\text { Anforderungen an die Verrechnungspreisdoku- } \\
\text { mentation sowie die Anwendung des „,deemed } \\
\text { pricing date“ spezifiziert. }\end{array}$ \\
\hline Nr. 11 & $\begin{array}{l}\text { Methoden zur } \\
\text { Informationsgewinnung } \\
\text { und-auswertung in Bezug } \\
\text { auf BEPS }\end{array}$ & $\begin{array}{l}\text { In Punkt } 11 \text { des OECD-Aktionsplans geht } \\
\text { es darum, das Ausmaß und die ökonomische } \\
\text { Relevanz von BEPS mithilfe von geeigneten } \\
\text { Indikatoren festzustellen. Ziel ist, sowohl Steu- } \\
\text { ervermeidungsstrategien als auch die hiergegen } \\
\text { gerichteten Aktionen beobachten und auswerten zu } \\
\text { können. Hierzu sollen sowohl bestehende Daten- } \\
\text { quellen analysiert als auch noch zu sammelnde } \\
\text { Daten identifiziert werden. Dabei sollen das } \\
\text { Steuergeheimnis und die administrativen Kosten } \\
\text { für Steuerverwaltung und Unternehmen beachtet } \\
\text { werden. }\end{array}$ \\
\hline
\end{tabular}




\begin{tabular}{l|l|l}
\hline Maßnahme & Titel & Inhalt \\
\hline Nr. 12 & Anzeigepflichten für & Der OECD Bericht zu Maßnahme 12 enthält \\
& Steuergestaltungen & Vorschläge für Regelungen zu zwingenden Offen- \\
& & legungspflichten für aggressive oder missbräuch- \\
& & liche Transaktionen, Modelle oder Strukturen \\
& unter Rückgriff auf die Erfahrungen und bereits \\
& & existierende Regelungen der OECD-Staaten. \\
& & Ferner ist die Ausarbeitung und Umsetzung ver- \\
& & besserter Modelle für den Informationsaustausch \\
& & zu Steuermodellen zwischen Steuerverwaltungen \\
& & verschiedener Staaten Ziel dieser Maßnahme. \\
\hline
\end{tabular}




\begin{tabular}{|c|c|c|}
\hline Maßnahme & Titel & Inhalt \\
\hline \multirow[t]{8}{*}{ Nr. 13} & \multirow[t]{8}{*}{$\begin{array}{l}\text { Überprüfung der } \\
\text { Verrechnungspreisdoku- } \\
\text { menta-tion }\end{array}$} & $\begin{array}{l}\text { Als Ergebnis der Maßnahme } 13 \text { hat die OECD } \\
\text { die finale Version des neuen Kapitels V der } \\
\text { OECD-Richtlinien zur Dokumentation von } \\
\text { Verrechnungspreisen veröffentlicht. Die OECD } \\
\text { will dabei das Transparenzbedürfnis der Steuer- } \\
\text { behörden auf der einen Seite und die Compliance- } \\
\text { Kosten für die Steuerzahler auf der anderen Seite } \\
\text { berücksichtigen. }\end{array}$ \\
\hline & & $\begin{array}{l}\text { Seitens der OECD ein dreistufiger Dokumenta- } \\
\text { tionsansatz vorgeschlagen: }\end{array}$ \\
\hline & & $\begin{array}{l}\text { 1. Master File: Stammdokumentation von standar- } \\
\text { disierten Informationen, die für alle Unternehmen } \\
\text { der Gruppe von Bedeutung sind, wie zum Beispiel } \\
\text { Informationen zu Organisationsstruktur oder } \\
\text { Geschäftsmodell. }\end{array}$ \\
\hline & & $\begin{array}{l}\text { 2. Local File: detaillierte landesspezifische } \\
\text { Dokumentation, die vornehmlich die relevanten } \\
\text { Informationen für die Verrechnungspreisanalyse } \\
\text { konzerninterner Transaktionen zwischen der loka- } \\
\text { len Einheit und verbundenen Unter-nehmen liefert. }\end{array}$ \\
\hline & & $\begin{array}{l}\text { 3. Country-by-Country-Report: Aufstellung der } \\
\text { globalen Verteilung bestimmter Kenn-zahlen wie } \\
\text { Umsatz, Vorsteuerergebnis, gezahlte Ertrag-steu- } \\
\text { ern, materielle Wirtschaftsgüter, Mitarbeiter etc., } \\
\text { gegliedert nach Steuerhoheitsgebieten (Tabelle 1); } \\
\text { zudem eine Aufstellung der Geschäftstätig- } \\
\text { keiten aller Geschäfts-einheiten (Tabelle 2) sowie } \\
\text { sonstige zusätzlich relevante Informationen } \\
\text { (Tabelle 3). Der CbCR ist für Unter nehmen mit } \\
\text { einem jährlichen konsolidierten Konzernumsatz } \\
\text { von mehr als } 750 \text { Millionen Euro zu erstellen. }\end{array}$ \\
\hline & & $\begin{array}{l}\text { Das neue Kapitel V der OECD-Leitlinien enthält } \\
\text { darüber hinaus Vorschläge zu verschiedenen Com- } \\
\text { pliance-Aspekten und zur Implementierung. }\end{array}$ \\
\hline & & $\begin{array}{l}\text { Am 22. März } 2016 \text { hat die OECD ein standardi- } \\
\text { siertes elektronisches Format für den Austausch } \\
\text { von CbC-Reportings, das sog. CbC XML-Schema, } \\
\text { samt dazugehörigem User Guide veröffentlicht. }\end{array}$ \\
\hline & & $\begin{array}{l}\text { Das Bundesministerium der Finanzen arbeitet } \\
\text { derzeit an der Überarbeitung bzw. Erweiterung } \\
\text { des } \$ 90 \text { AO sowie der GAufzV. Die Verwaltungs- } \\
\text { grundsätze-Verfahren sollen ebenfalls überarbeitet } \\
\text { werden. Seit dem } 11 \text {. April } 2016 \text { liegt ein Referen- } \\
\text { tenentwurf des BMF für ein Gesetz zur Mehrseiti- } \\
\text { gen Vereinbarung verschiedener Staaten vom } 27 . \\
\text { Januar } 2016 \text { zwischen den zuständigen Behörden } \\
\text { über den Austausch länderbezogener Berichte } \\
\left(, \mathrm{CbCR}^{\circ)} \text { vor. }\right.\end{array}$ \\
\hline
\end{tabular}




\begin{tabular}{|c|c|c|}
\hline Maßnahme & Titel & Inhalt \\
\hline \multirow[t]{5}{*}{ Nr. 14} & \multirow[t]{5}{*}{$\begin{array}{l}\text { Verbesserung der Effizienz } \\
\text { von Streitbeilegungsme- } \\
\text { chanismen }\end{array}$} & $\begin{array}{l}\text { Der Fokus des OECD-Berichts zu Maßnahme } \\
14 \text { ist auf die Beseitigung von Hindernissen bei } \\
\text { der Durchführung von Verständigungsverfahren } \\
\text { gerichtet sowie auf die Tatsache, dass zahlreiche } \\
\text { Doppelbesteuerungsabkommen (DBA) keine } \\
\text { Schiedsverfahrensregularien enthalten und somit } \\
\text { der Zugang zu einer endgültigen bindenden Vermei- } \\
\text { dung der Doppelbesteuerung teilweise verwehrt ist. }\end{array}$ \\
\hline & & $\begin{array}{l}\text { Im Rahmen der BEPS-Maßnahme } 14 \text { wurde nun- } \\
\text { mehr ein Mindeststandard im Hinblick auf die } \\
\text { Streitbeilegung festgelegt. Dieser soll Folgendes } \\
\text { festlegen: }\end{array}$ \\
\hline & & $\begin{array}{l}\text { 1. Sicherstellung, dass die Abkommensverpflich- } \\
\text { tungen in Bezug auf Verständigungsverfahren } \\
\text { vollständig nach den Grundsätzen von Treu und } \\
\text { Glauben implementiert sind und die Streitfälle zeit- } \\
\text { nah gelöst werden, }\end{array}$ \\
\hline & & $\begin{array}{l}\text { 2. Sicherstellung der Implementierung adminis- } \\
\text { trativer Prozesse, die die Vermeidung und zeitnahe } \\
\text { Lösung von Streitfällen fördern, und }\end{array}$ \\
\hline & & $\begin{array}{l}\text { 3. Sicherstellung, dass Steuerpflichtige Verstän- } \\
\text { digungsverfahren anstreben können, sofern dies } \\
\text { angemessen ist. }\end{array}$ \\
\hline Nr. 15 & $\begin{array}{l}\text { Entwicklung eines multi- } \\
\text { lateralen Instruments zur } \\
\text { Modifikation bilateraler } \\
\text { DBA }\end{array}$ & $\begin{array}{l}\text { Die einzelnen, zu den jeweiligen BEPS-Aktions- } \\
\text { punkten vereinbarten Maßnahmen entfalten in den } \\
\text { betreffenden Staaten nicht ohne Weiteres rechtli- } \\
\text { che Wirkung. Sie müssen vielmehr in bilateralen } \\
\text { Doppelbesteuerungsabkommen (DBA) bzw. } \\
\text { nationalen Steuergesetze umgesetzt werden. Die } \\
\text { BEPS Initiative zielt darauf ab, Gewinnverkür- } \\
\text { zungen und Gewinnverlagerungen bei grenzüber- } \\
\text { schreitenden Transaktionen zu verhindern. Daher } \\
\text { ist ein Teil der BEPS-Maßnahmen direkt auf die } \\
\text { Anpassung bzw. Änderung von DBA gerichtet. } \\
\text { Doch auch bei der Umsetzung in nationale Steu- } \\
\text { ergesetze können DBA betroffen sein, wenn die } \\
\text { nationalen Regelungen zu den DBA-Regelungen } \\
\text { im Widerspruch stehen. }\end{array}$ \\
\hline
\end{tabular}

Aus Verrechnungspreissicht relevant sind insbesondere die BEPS Maßnahmen 7 (Betriebsstätten), 8-10 (Immaterielle Wirtschaftsgüter) und 13 (Verrechnungspreisdokumentation und länderbezogene Berichterstattung). 
Inhalt der BEPS Maßnahme 7 sind schwerpunktmäßig folgende Punkte (Art. 5 OECDMusterabkommen): ${ }^{54}$

- Erweiterung des Betriebsstättenbegriffs auf bestimmte Kommissionärsstrukturen

- Neudefinition der vorbereitenden und Hilfstätigkeiten

- Einführung einer Antifragmentierungsregelung

Bzgl. des Themenbereichs Immaterielle Wirtschaftsgüter und Risiko hat die OECD im Wesentlichen die folgenden Aspekte geregelt: ${ }^{55}$

- Guidance for Applying the Arm's Length Principle (Kap. I Abschnitt D der OECD-Verrechnungspreisleitlinien)

Anwendung des Fremdvergleichs auf die Transaktionsstruktur zwischen Konzernunternehmen, insbesondere Übernahme von Risiken

- Commodity Transactions (Kap. II der OECD-Verrechnungspreisleitlinien)

Anforderungen bzgl. der vorrangig zu verwendenden Methoden bei Warentransaktionen mit öffentlicher Preisfestsetzung

- Scope of Work for Guidance on the Transactional Profit Split Method Vorläufige Ausarbeitungen bzgl. der Anwendung des Profit Splits

- Intangibles (Kap. VI der OECD-Verrechnungspreisleitlinien)

Einführung einer breiten, klar abgegrenzten Definition von immateriellen Werten (IWG) für Verrechnungspreiszwecke, Vorschriften zu Verrechnungspreisen oder speziellen Maßnahmen in Bezug auf Übertragungen schwer zu bewertender immaterieller Werte (HTVI - hard to value intangibles)

- Low Value-adding Intra-group Services (Kap. VII der OECD-Verrechnungspreisleitlinien) Dokumentation und Vergütung von Dienstleistungen mit geringer Wertschöpfung

- Cost Contribution Arrangements (Kap. VIII der OECD-Verrechnungspreisleitlinien)

Die Überarbeitung der Leitlinien zu Kostenumlagevereinbarungen (CCA)

Die OECD BEPS Maßnahme 13 beschäftigt sich mit den Anforderungen an die Verrechnungspreisdokumentation. ${ }^{56}$ Die OECD sieht in der Neufassung des Kapitels V der OECD-Verrechnungspreisleitlinien einen dreistufigen Dokumentationsansatz bestehend aus Master File, Local File und Country-by-Country Reporting vor. Das neue Kap. V der OECD-Leitlinien enthält darüber hinaus Vorschläge zu verschiedenen ComplianceAspekten und zur Implementierung.

\footnotetext{
${ }^{54}$ S. zu Betriebsstätten Kap. 2.5 dieses Buchs.

${ }^{55}$ S. hierzu Kap. 5 dieses Buchs.

${ }^{56}$ S. zur Verrechnungspreisdokumentation Kap. 3 dieses Buchs.
} 


\subsection{Verfahrensrechtliche Vorschriften}

\subsubsection{Mitwirkungspflichten des Steuerpflichtigen}

„Steuern sind Geldleistungen, die nicht eine Gegenleistung für eine besondere Leistung darstellen und von einem öffentlich-rechtlichen Gemeinwesen zur Erzielung von Einnahmen allen auferlegt werden, bei denen der Tatbestand zutrifft, an den das Gesetz die Leistungspflicht knüpft; die Erzielung von Einnahmen kann Nebenzweck sein “. ${ }^{57}$ Die Erhebung von Steuern greift somit explizit in das Eigentumsrecht der einzelnen Bürger ein, um dem Staat die Möglichkeit zu verschaffen, Einnahmen zu erzielen. Aufgrund dieser Sensibilität ist das Verfahren zur Steuererhebung gesetzlich streng normiert. Insbesondere haben die Finanzverwaltungen die Aufgabe Steuern gleichmäßig festzusetzen und sicherzustellen, dass Steuern nicht verkürzt oder Steuervergütungen zu Unrecht begeben oder versagt werden. Die Finanzverwaltung ist bei der Untersuchung nicht an Beweisanträge der Verfahrensbeteiligten gebunden. Sie bestimmt die Art und den Umfang der Untersuchungen. Sie „hat alle für den Einzelfall bedeutsamen, auch die für die Beteiligten günstigen Umstände zu berücksichtigen“" (vgl. § 88 Abs. 2 AO).

Grundsätzlich ist der Steuerpflichtige nicht dazu verpflichtet, der Finanzverwaltung Beweismittel zur Verfügung zu stellen, es sei denn, er wird durch eine gesetzliche Regelung hierzu verpflichtet. Dementsprechend wird der Untersuchungsauftrag der Finanzverwaltung um Mitwirkungspflichten des Steuerpflichtigen ergänzt. Der Steuerpflichtige ist somit im Rahmen dieser Mitwirkungspflichten verpflichtet, mit der Finanzverwaltung zusammenzuarbeiten. Generell ist die Mitwirkung des Steuerpflichtigen in $\S 90$ AO geregelt. Zudem sind spezielle Mitwirkungspflichten des Steuerpflichtigen bei einer steuerlichen Außenprüfung gem. § $200 \mathrm{AO}$ geregelt.

Die Mitwirkungspflicht gem. § $90 \mathrm{AO}$ gliedert sich folgendermaßen:

- Verpflichtung zur Mitwirkung bei der Ermittlung des Sachverhalts

- Erweiterte Mitwirkungspflichten bei Auslandssachverhalten

- Dokumentationsvorschriften bei Auslandssachverhalten

Die Mitwirkungspflichten der Beteiligten bzgl. konzerninterner grenzüberschreitender Transaktionen werden insbesondere durch die GAufzV und durch die VWGV weiter konkretisiert. Die VWGV haben ausschließlich Bindungswirkung für die Finanzverwaltung, nicht aber für den Steuerpflichtigen oder die Gerichte. Trotzdem ergeben sich gerade hinsichtlich der Frage des Ausmaßes der Mitwirkungspflichten des Steuerpflichtigen regelmäßig Diskussionen mit der Finanzverwaltung.

Gemäß $§ 1$ GAuzV muss aus den nach $\S 90$ Abs. 3 der Abgabenordnung zu erstellenden Aufzeichnungen ersichtlich sein, welchen Sachverhalt der Steuerpflichtige im Rahmen seiner Geschäftsbeziehungen mit nahe stehenden Personen verwirklicht hat und ob

${ }^{57}$ Vgl. $\S 3$ AO. 
und inwieweit er diesen Geschäftsbeziehungen Bedingungen einschließlich von Preisen zu Grunde gelegt hat, die erkennen lassen, dass er den Grundsatz des Fremdverhaltens (Fremdvergleichsgrundsatz) beachtet hat (Aufzeichnungen). Die Aufzeichnungen müssen das ernsthafte Bemühen des Steuerpflichtigen belegen, seine Geschäftsbeziehungen zu nahe stehenden Personen unter Beachtung des Fremdvergleichsgrundsatzes zu gestalten. Die Beweislast für die Fremdüblichkeit der Verrechnungspreise liegt folglich bei der Finanzverwaltung.

Jedoch bestehen auch Grenzen der Aufzeichnungspflicht. Die Mitwirkungspflichten des Steuerpflichtigen sind auf die Vorlage von Unterlagen beschränkt, deren Beschaffung für die Gesellschaft rechtlich oder tatsächlich möglich ist (s. Tz. 3.3.3 b) VWGV). Nach Auffassung des BFH ist es einer Gesellschaft regelmäßig unmöglich, Beweisvorsorge für Auskünfte bzw. Unterlagen der ausländischen Mutter- bzw. Schwestergesellschaft zu treffen. Der Steuerpflichtige ist nur verpflichtet, Beweisvorsorge für die Verhältnisse der ihm nachgeordneten Gesellschaften zu betreiben. Eine Mitwirkungspflicht der Tochtergesellschaft besteht aber für die Verhältnisse der Muttergesellschaft bzw. der Schwestergesellschaften nicht. In seinem Beschluss vom 10.5.2001 (I S 3/01, BFHE 194, 360) führt der BFH hierzu aus, dass eine inländische Tochtergesellschaft regelmäßig keine Möglichkeit hat, Kalkulationsunterlagen ihrer ausländischen Muttergesellschaft zu beschaffen. Nach Auffassung des BFH ist die Erteilung von Auskünften zwischen fremden Dritten nicht nur unüblich, sondern für den Regelfall ausgeschlossen. Unabhängige Vertragspartner sind nicht bereit, ihre wechselseitig erzielten Gewinne dem jeweils anderen Vertragsteil mitzuteilen. Sie tun dies schon deshalb nicht, weil sie zusätzlichen Druck des anderen Geschäftspartners auf die eigenen Preise befürchten. Sie verzichten auch nicht auf das Geschäft, wenn der andere Vertragspartner sich weigert, Auskunft über seine Gewinne zu erteilen. Der BFH stellt damit hinsichtlich der Möglichkeit zur Beschaffung von Unterlagen zutreffend auf den Fremdvergleich ab und kommt zu dem Schluss, dass im Verhältnis miteinander verbundener Unternehmen die Vorlage bestimmter Unterlagen und Informationen nicht verlangt werden kann, wenn sich fremde Dritte eine entsprechende Informationsmöglichkeit nicht einräumen würden.

\subsubsection{Erweiterte Aufzeichnungspflichten gem. $§ 90$ Abs. 3 AO}

Mit dem Gerichtsurteil vom 17.10.200158 entschied der Bundesfinanzhof, dass eine Pflicht zur Dokumentation konzerninterner Verrechnungspreise, insbesondere der Darstellung der Fremdüblichkeit dieser Verrechnungspreise, nicht durch die bisherige Gesetzgebung gedeckt gewesen ist.

Als Reaktion hierauf wurde $\S 90$ Abs. 3 AO in 2003 in die Abgabenordnung aufgenommen. Die Mitwirkungspflichten des Steuerpflichtigen wurden hiermit um die

${ }^{58}$ BFH, Urteil vom 17.10.2001- I R 103-00. Konzernverrechnungspreise als vGA einer Vertriebsgesellschaft. 
Verpflichtung zur Dokumentation konzerninterner Verrechnungspreise erweitert. Zur weiteren Konkretisierung wurde eine Rechtsverordnung, die GAufzV erlassen. Die deutsche Finanzverwaltung erließ zudem ein BMF Schreiben, die sogenannten VWGV, welche die Interpretation sowohl des $\S 90$ Abs. 3 AO als auch der GAufzV aus Sicht der Finanzverwaltung widerspiegeln. Wie bereits vorstehend dargestellt, sind die VWGV ausschließlich für die Finanzverwaltung bindend und binden weder die Gerichte noch den Steuerpflichtigen. Ein Abweichen von den in den VWGV genannten Regelungen kann aber im Zweifel zu Konflikten mit der deutschen Finanzverwaltung führen, die anschließend nur durch Verständigungsverfahren bzw. durch die Anrufung nationaler Gerichte geklärt werden können.

Um die Durchsetzung der Verrechnungspreisdokumentationspflichten sicherzustellen, wurden zusätzlich Straf- und Schätzvorschriften bei Verletzung der Dokumentationspflichten implementiert. Im Folgenden werden die zu dokumentierenden Geschäftsvorfälle, die Frage der Beweislast in einer Betriebsprüfung sowie die ergänzenden Straf- und Schätzvorschriften dargestellt:

\section{Zu dokumentierende Geschäftsvorfälle}

Die GAufzV und die VWGV verlangen, dass der Steuerpflichtige Aufzeichnungen über den Sachverhalt erstellt, den er im Rahmen seiner Transaktionen mit nahe stehenden Personen verwirklicht hat (Sachverhaltsdokumentation). Zusätzlich muss die Dokumentation das ernstliche Bemühen erkennen lassen, dass der Steuerpflichtige den Fremdvergleichsgrundsatz beachtet hat (Angemessenheitsdokumentation). Die Aufzeichnungspflicht umfasst alle relevanten Sachverhalte über Geschäftsbeziehungen, die einen Leistungsaustausch mit verbundenen Unternehmen oder nahe stehenden Personen zum Gegenstand haben, aber auch Vereinbarungen wie z. B. Personalentsendungen oder Kostenumlageverträge. Aus den Aufzeichnungen sollen Art, Umfang und Abwicklung sowie die wirtschaftlichen und rechtlichen Rahmenbedingungen der Geschäftsbeziehung ersichtlich werden.

Gewöhnliche Geschäftsvorfälle umfassen sämtliche Transaktionen, die nicht zu den außergewöhnlichen Geschäftsvorfällen gehören.

Der Steuerpflichtige ist nicht dazu verpflichtet, eine Verrechnungspreisdokumentation kontinuierlich vorzuhalten. Eine Verrechnungspreisdokumentation ist aber innerhalb von 60 Tagen nach Anforderung der deutschen Finanzverwaltung abzugeben. Diese Anforderung soll normalerweise nur im Rahmen einer steuerlichen Außenprüfung erfolgen. ${ }^{59}$ Zudem kann die Betriebsprüfung zwar in den Fällen, in denen sich die Geschäftsbereiche und die Geschäftsbeziehungen des Steuerpflichtigen nicht aus den Akten bereits ergeben, für das Gesamtunternehmen Aufzeichnungen anfordern. Jedoch müsste die Funktionsund Risikoanalyse sowie die Verrechnungspreisanalyse für bestimmte Geschäftsbereiche anschließend gesondert angefordert werden. ${ }^{60}$

${ }^{59}$ Vgl. $§ 90$ Abs. 3 S. 6 AO.

${ }^{60}$ Schreiber in Kroppen, Handbuch Internationale Verrechnungspreise, VerwGr.Verf., Anm. 24. 
Erfahrungsgemäß ist es normalerweise nicht möglich, eine Verrechnungspreisdokumentation innerhalb dieser Zeitspanne anzufertigen. Zudem sind häufig auch die betreffenden Mitarbeiter, die über das notwendige Sachverhaltsverständnis verfügen, nicht mehr verfügbar, da sie entweder das Unternehmen verlassen oder andere Aufgabengebiete zugewiesen bekommen haben. Dementsprechend ist trotz fehlender gesetzlicher Regelung eine kontinuierliche Verrechnungspreisdokumentation zu empfehlen.

Die Anwendung der Verrechnungspreisdokumentationsregelungen wird in Kap. 3 dieses Buches diskutiert. Insofern werden im Folgenden die entsprechenden Anforderungen kurz dargestellt:

Die Dokumentationsvorschriften sind in der GAufzV verankert. Eine schriftliche Verrechnungspreisdokumentation ist für sämtliche Geschäftsbeziehungen mit ausländischen nahestehenden Personen sowie Betriebsstätten anzufertigen. Die GAufzV ist folgendermaßen gegliedert:

$\S 1$ Grundsätze der Aufzeichnungspflicht

$\S 2$ Art, Inhalt und Umfang der Aufzeichnungen

$\S 3$ Zeitnahe Erstellung von Aufzeichnungen bei außergewöhnlichen Geschäftsvorfällen

$\S 4$ Allgemein erforderliche Aufzeichnungen

$\S 5$ Erforderliche Aufzeichnungen in besonderen Fällen

$\S 6$ Anwendungsregelungen für kleinere Unternehmen und Steuerpflichtige mit anderen als Gewinneinkünften

$\S 7$ Entsprechende Anwendung bei Betriebsstätten und Personengesellschaften

Die erforderlichen Aufzeichnungen in besonderen Fällen gelten entsprechend $\S 3$ Abs. 1 GAufzV als zeitnah erstellt, wenn Sie innerhalb von 6 Monaten nach Abschluss des Wirtschaftsjahres erstellt worden sind, in dem der außergewöhnliche Geschäftsvorfall abgeschlossen worden ist. Als außergewöhnliche Geschäftsvorfälle werden insbesondere angesehen ( 3 Abs. 2 GAufzV):

- Der Abschluss und die Änderung langfristiger Verträge, die sich erheblich auf die Höhe der Einkünfte des Steuerpflichtigen aus seinen Geschäftsbeziehungen auswirken

- Vermögensübertragungen im Zuge von Umstrukturierungsmaßnahmen

- Übertragung und Überlassung von Wirtschaftsgütern und Vorteilen im Zusammenhang mit wesentlichen Funktions- und Risikoänderungen im Unternehmen

- Geschäftsvorfälle im Zusammenhang mit einer für die Verrechnungspreisbildung erheblichen Änderung der Geschäftsstrategie

- Abschluss von Umlageverträgen

Grundsätzlich sind alle Steuerpflichtigen mit Geschäftsbeziehungen zu nahestehenden Personen sowie Betriebsstätten im Ausland dokumentationspflichtig. Jedoch gibt es Ausnahmeregelungen für kleinere und mittlere Unternehmen, $§ 6$ GAufzV. Bei kleineren und mittleren Unternehmen gelten die Dokumentationspflichten mit der Erteilung von Auskünften und durch die Vorlage vorhandener Unterlagen auf Anforderung des Finanzamts 
als erfüllt. Die Grenzen betragen hierbei 5.000.000 EUR für die Lieferung bzw. den Bezug von Waren an bzw. von nahestehenden Personen sowie 500.000 EUR für den Bezug bzw. die Bereitstellung von Dienstleistungen bzw. anderen Transaktionen. Es ist zu beachten, dass die Transaktionen deutscher Konzerngesellschaften im Sinne der $\S \S 13,18$ und 19 der Betriebsprüfungsordnung zusammen betrachtet werden. Es ist insofern nicht möglich, die erweiterten Aufzeichnungspflichten durch eine „Atomisierung“ der Geschäftsbeziehungen mit nahestehenden Personen zu umgehen.

In Fällen, in denen Steuerpflichtige andere Einkünfte als Gewinneinkünfte beziehen, gelten die vorstehend dargestellten Größenbeschränkungen nicht. Bei diesen Steuerpflichtigen sind die Dokumentationspflichten immer mit den vorstehend dargestellten Auskünften bzw. vorzulegenden Unterlagen abgegolten. $\mathrm{Zu}$ den Gewinneinkünften zählen Einkünfte aus Land- und Forstwirtschaft gem. § 13, § 14 EStG, Einkünfte aus Gewerbebetrieb gem. § 15-§ 17 EStG und Einkünfte aus selbstständiger Tätigkeit gem. § 18 EStG. Es ist hierbei zu beachten, dass Kapitalgesellschaften ausschließlich Einkünfte aus Gewerbebetrieb beziehen. Jedoch kann diese Ausnahmeregelung bspw. für Privatpersonen, die an eine von ihnen gehaltene ausländische Kapitalgesellschaft Darlehen begeben haben und hieraus Zinseinkünfte beziehen, gelten.

\subsubsection{Beweislast/Beweismaß}

Grundlage jedes Gerichtsurteils ist der jeweilige zugrundeliegende Sachverhalt. Die Finanzverwaltung hat aufgrund des Untersuchungsgrundsatzes nach $\S 88 \mathrm{AO}$ den Auftrag, den Sachverhalt von Amts wegen aufzuklären. Anhand des dabei gewonnenen Sachverhaltsverständnisses fällen die jeweiligen Gerichte (Finanzgerichte und als Folgeinstanz der Bundesfinanzhof) ihre Urteile. Entscheidend ist hierbei die Frage der Beweislastverteilung. Will die Finanzverwaltung eine Einkünftekorrektur vornehmen, so liegt die Beweislast bei der Finanzverwaltung. Diese hat die Konsequenzen zu tragen, wenn der zugrunde liegende Sachverhalt trotz Mitwirkung des Steuerpflichtigen nicht mit dem erforderlichen Grad der Gewissheit aufgeklärt werden kann. Der erforderliche Grad der Gewissheit kann jedoch reduziert sein, wenn und soweit der Steuerpflichtige seine gesetzlichen Mitwirkungspflichten verletzt. Der Besteuerung kann in diesen Fällen ein Sachverhalt zugrunde gelegt werden, für den die größte Wahrscheinlichkeit spricht. Dies bedeutet aber keine Umkehrung der Beweislast, sondern nur eine Reduzierung des Beweismaßes.

\subsubsection{Verletzung der Aufzeichnungspflichten}

Ein Steuerpflichtiger kann die allgemeinen Mitwirkungspflichten, die erweiterten Mitwirkungspflichten bei Auslandssachverhalten oder die Dokumentationspflichten verletzen. Eine Verletzung der Aufzeichnungspflichten kann durch die Finanzverwaltung geahndet werden. Im Folgenden wird auf diese Regelungen näher eingegangen. 
Eine Verletzung der allgemeinen Mitwirkungspflichten kann dazu führen, dass ein Sachverhalt nicht aufgeklärt werden kann. In diesem Fall kann eine Schätzung der Besteuerungsgrundlagen durchgeführt werden. ${ }^{61}$ Auch eine Schätzung muss jedoch den objektiven Sachverhalt berücksichtigen, jedoch ist bei einer Schätzung der Grad des Beweismaßes erheblich geringer.

Im Einzelnen sieht das Gesetz die folgenden (Straf-) Zuschläge vor:

Tab. 2.2 Übersicht (Straf-) Zuschläge

\begin{tabular}{|c|c|c|c|c|}
\hline Pflichtverletzung & $\begin{array}{l}\text { Einkünf- } \\
\text { tekorrek- } \\
\text { tur }\end{array}$ & Minimum & Bandbreite & Maximum \\
\hline $\begin{array}{l}\text { Keine oder im wesentlichen } \\
\text { unverwertbare Aufzeich- } \\
\text { nungen vorgelegt ( } \S 162 \\
\text { Abs. } 4 \text { Satz } 1,2 \text { i. V. m. } \\
\S 90 \text { Abs. } 3 \text { AO) }\end{array}$ & $\mathrm{Ja}$ & $5000 €$ & $\begin{array}{l}5-10 \% \text { des } \\
\text { Mehrbetrags der } \\
\text { Einkünfte nach } \\
\text { Berichtigung }\end{array}$ & $\begin{array}{l}\text { Kein absolutes } \\
\text { Maximum }\end{array}$ \\
\hline $\begin{array}{l}\text { Keine oder im wesentlichen } \\
\text { unverwertbare Aufzeich- } \\
\text { nungen vorgelegt }\end{array}$ & Nein & $\begin{array}{l}5000 € \\
\text { (Festbetrag) }\end{array}$ & & \\
\hline $\begin{array}{l}\text { Verspätete Vorlage der Auf- } \\
\text { zeichnungen ( } \$ 162 \text { Abs. } 4 \\
\text { Satz } 3 \text { i. V. m. } § 90 \text { Abs. } 3 \\
\text { AO) }\end{array}$ & $\mathrm{Ja} /$ nein & $\begin{array}{l}\text { Mindestens } \\
100 € \text { für jeden } \\
\text { vollen Tag } \\
\text { der Fristüber- } \\
\text { schreitung }\end{array}$ & & $1.000 .000 €$ \\
\hline
\end{tabular}

Nach nationalem Recht wird der Zuschlag von 5-10\% auf den Mehrbetrag der Einkünfte nach einer Berichtigung vorgenommen, während andere Staaten einen Zuschlag nur auf die tatsächlichen Mehrsteuern erheben.

Mit Wirkung zum Veranlagungszeitraum 2008 gelten diese erweiterten Schätzbefugnisse auch in den Fällen, in denen ausländische nahestehende Personen des Steuerpflichtigen ihre Mitwirkungspflichten gem. § 90 Abs. 2 AO bzw. $§ 93$ Abs. 1 AO verletzt haben. Die deutsche Finanzverwaltung ist in diesen Fällen dazu berechtigt, den Schätzrahmen zu Lasten des Steuerpflichtigen auszuschöpfen. ${ }^{62}$ Umstritten ist hierbei, inwieweit diese Regelungen tragfähig sind. Erstens ist unklar, ob ausländische nahestehende Personen überhaupt Mitwirkungspflichten unterliegen können. Die Mitwirkungspflichten richten sich gem. § 78 AO grundsätzlich nur an Beteiligte. Eine ausländische nahestehende Person ist allerdings weder Antragsteller noch Antragsgegner i. S. d. § 78 Nr. 1 AO. Zudem will die Finanzverwaltung an die verbundene Auslandsgesellschaft keinen Verwaltungsakt (hier den Schätzungsbescheid) richten (§ 78 Nr. 2 AO), sondern an den inländischen Steuerpflichtigen. Schließlich will die Finanzbehörde mit der ausländischen nahestehen-

${ }^{61}$ Vgl. $\$ 162$ Abs. 2 AO.

${ }^{62} \mathrm{Vgl}$ § 162 Abs. 3 AO. 
den Person auch keinen öffentlich-rechtlichen Vertrag schließen (§ 78 Nr. 3 AO). Folglich ist die ausländische Konzerngesellschaft kein Beteiligter, der nach $\S 90$ Abs. 2 AO mitwirkungspflichtig ist. Die Regelung des $\S 162$ Abs. 3 AO wäre insofern im Hinblick auf die Verletzung der Mitwirkungspflichten durch ausländische nahestehende Personen nicht anwendbar.

Auch der erweiterte Schätzrahmen gibt der Finanzverwaltung nicht das Recht zu einer Strafschätzung. Eine entsprechende Schätzung kann ausschließlich im Bereich einer sachgerechten Bandbreite erfolgen.

Eine Verletzung der allgemeinen Mitwirkungspflichten kann dazu führen, dass Verzögerungsgelder, Zwangsgelder etc. angewandt werden. Insbesondere wurde durch einzelne Länderfinanzverwaltungen die Anwendung eines Verzögerungsgeldes nach $\S 146$ Abs. 2b AO angeregt. Diese Norm, die seit dem Veranlagungszeitraum 2008 in Kraft ist, bezieht sich auf das Führen von Büchern im Ausland, allerdings kann auch bei einer sonstigen verzögerten Beibringung von Unterlagen bei einer Betriebsprüfung ein Verzögerungsgeld nach $\S 146$ Abs. 2b AO festgelegt werden. Da es wie untenstehend dargestellt jedoch explizite Regelungen betreffend Verspätungszuschlägen bei einer verspäteten Abgabe einer verwertbaren Dokumentation bzw. bei der Vorlage einer nicht verwertbaren Dokumentation gibt, ist die zusätzliche Anwendung des Verzögerungsgeldes gem. § 146 Abs. 2b AO nicht sachgerecht.

Eine Unverwertbarkeit der Verrechnungspreisdokumentation liegt grundsätzlich nur dann vor, wenn die Dokumentation der Nichtabgabe einer Verrechnungspreisdokumentation gleichkommt. Selbst schwere Mängel führen nicht zu einer Unverwertbarkeit der Verrechnungspreisdokumentation. ${ }^{63}$

Nach Meinung der Finanzverwaltung ist eine Verrechnungspreisdokumentation dann verwertbar, ,wenn sie einem sachverständigen Dritten innerhalb angemessener Zeit die Feststellung und Prüfung ermöglichen, welche Sachverhalte vom Steuerpflichtigen verwirklicht wurden und ob und inwieweit der Steuerpflichtige dabei den Fremdvergleichsgrundsatz beachtet hat" ${ }^{64}$ Unabhängig davon kann sich die Frage der Verwertbarkeit der Verrechnungspreisdokumentation nur auf die jeweilige Transaktion erstrecken. Eine Unverwertbarkeit bzgl. einer Transaktion führt noch nicht zu einer Unverwertbarkeit der Verrechnungspreisdokumentation in Bezug auf weitere Transaktionen.

Wie dargestellt müssen außergewöhnliche Geschäftsvorfälle durch den Steuerpflichtigen zeitnah dokumentiert werden. Außergewöhnliche Geschäftsvorfälle gelten als diese zeitnah dokumentiert, wenn sie innerhalb von 6 Monaten nach Ablauf des Wirtschaftsjahres, in dem der außergewöhnliche Geschäftsvorfall stattgefunden hat, dokumentiert werden. Die betreffende Verrechnungspreisdokumentation muss jedoch innerhalb von 30 Tagen nach Anforderung durch die Finanzverwaltung durch den Steuerpflichtigen vorgelegt werden. Diese Vorlagefrist ist unabhängig von der Pflicht des Steuerpflichtigen, diese zeitnah zu erstellen. Zwar ist die Durchsetzung der Pflicht zur zeitnahen Dokumentation außer-

${ }^{63}$ Schreiber in Kroppen, Handbuch Internationale Verrechnungspreise, VerwGr.Verf., Anm. 266. ${ }^{64}$ Vgl. VWGV Tz. 3.4.19. 
gewöhnlicher Geschäftsvorfälle nicht durch spezielle Bußgeldvorschriften sanktioniert. Sollte der Steuerpflichtige die Verrechnungspreisdokumentation für den außergewöhnlichen Geschäftsvorfall nicht zeitnah angefertigt haben, wird allerdings widerlegbar vermutet, dass die Einkünfte des Steuerpflichtigen höher als die von ihm erklärten Einkünfte sind. Hat in diesem Falle eine Schätzung zu erfolgen, kann die Finanzverwaltung, wie auch bei der vorstehend dargestellten Verletzung der erweiterten Mitwirkungspflichten bei Auslandssachverhalten, den Schätzrahmen zu Lasten des Steuerpflichtigen ausnutzen. ${ }^{65}$

Der deutschen Finanzverwaltung wird es somit im Falle der Nichtabgabe einer Verrechnungspreisdokumentation bzw. der Vorlage einer unverwertbaren Verrechnungspreisdokumentation erleichtert, Verrechnungspreiskorrekturen zuungunsten des Steuerpflichtigen vorzunehmen. Die Anpassungen des zu versteuernden Einkommens sind dementsprechend tendenziell höher als in den Fällen, in denen der Steuerpflichtige seinen Mitwirkungspflichten in vollem Umfang nachgekommen ist. Zusätzlich zu diesen erhöhten Verrechnungspreisanpassungen erhebt die deutsche Finanzverwaltung auch Zuschläge im Falle der Abgabe einer unverwertbaren bzw. der Nichtabgabe einer Dokumentation. Dieser Zuschlag in Höhe von 5-10\% der Einkommenskorrektur wird unabhängig von der tatsächlichen Steuernachzahlung verhängt. Er bezieht sich ausschließlich auf die Änderung des zu versteuernden Einkommens. Eine Einkommenskorrektur in Höhe von 500.000 EUR würde insofern einen Strafzuschlag bis zu einer Höhe von 50.000 EUR auslösen. Insofern können also auch bei Vorliegen signifikanter Verlustvorträge und hoher steuerlicher Verluste in den betreffenden Jahren signifikante Zuschläge aufgrund der Nichtbefolgung steuerlicher Mitwirkungspflichten eintreten.

Zusammenfassend betrachtet wurden für die Finanzverwaltung im vergangenen Jahrzehnt umfassende gesetzliche Sanktionsmöglichkeiten gegenüber dem Steuerpflichtigen geschaffen. Es ist zu beobachten, dass Zuschläge von den jeweiligen Finanzverwaltungen verstärkt verhängt werden. Insbesondere werden auch früher als ausreichend angesehene Verrechnungspreisdokumentationen immer häufiger von der Finanzverwaltung als unverwertbar angesehen. Aufgrund der dargestellten vielfältigen Sanktionsmöglichkeiten der Finanzverwaltung ist es insofern für den jeweiligen Steuerpflichtigen absolut notwendig, eine ausreichende Verrechnungspreisdokumentation vorzuhalten, um Fragen der Beweislast sowie der Verhängung von Zuschlägen bereits im Vorhinein aus dem Weg gehen zu können und mit der Finanzverwaltung über die Fremdüblichkeit der Verrechnungspreise und nicht über Verfahrensfahren diskutieren zu müssen.

\subsubsection{Methoden zur Vermeidung der Doppelbesteuerung}

Grundsätzliches Ziel der Doppelbesteuerungsabkommen ist es, das Besteuerungssubstrat zwischen den einzelnen Staaten sachgerecht aufzuteilen und dabei eine Doppelbesteuerung des Besteuerungssubstrats zu vermeiden. Der Staat, dem das Besteuerungsrecht an

${ }^{65}$ Vgl. Tz. 4.6.1 VWGV. 
den Einkünften nicht zusteht, hat diese Einkünfte entweder (ggf. unter Progressionsvorbehalt) freizustellen (Freistellungsmethode) oder die ausländische Steuer auf die eigene Steuerlast anzurechnen (Anrechnungsmethode). Im Ergebnis sollte dies mögliche Doppelbesteuerungen verhindern.

Eine Doppelbesteuerung tritt jedoch immer dann ein, wenn die jeweiligen Finanzverwaltungen die Einkünfte unterschiedlich voneinander abgrenzen. Dies betrifft häufig den Fall von Leistungsbeziehungen zwischen verbundenen Unternehmen. Solange beide Finanzverwaltungen die zwischen den Unternehmen angewandten Verrechnungspreise nicht korrigieren, kommt es in den einzelnen Staaten nicht zu einer Doppelbesteuerung. Der Ertrag aus einer Transaktion wird nur einmal besteuert. Sobald jedoch eine Finanzverwaltung die originär zwischen den verbundenen Unternehmen angewandten Verrechnungspreise korrigiert (unabhängig davon, ob diese Korrektur sachgerecht ist oder nicht), kommt es zunächst zu einer Doppelbesteuerung.

In Deutschland steht dem Steuerpflichtigen in diesem Fall der Weg des Einspruchs gegen die nach einer Betriebsprüfung ergangenen geänderten Steuerbescheide, welche die Einkommenskorrektur beinhalten, und danach der Klageweg offen. Allerdings kann im Rahmen einer Klage die Doppelbesteuerung nur dann beseitigt werden, wenn der Steuerpflichtige mit seinem Begehren vollständig obsiegt. Nimmt die Finanzverwaltung eine Verletzung von Mitwirkungspflichten an und verhängt deswegen Strafzahlungen, kann dies allerdings der einzig gangbare Weg sein.

Daneben besteht zumindest theoretisch die Möglichkeit, eine unilaterale Gegenkorrektur in dem anderen Staat durchzuführen. So regelt Art. 9 Abs. 2 des OECD-MA Folgendes: „Werden in einem Vertragsstaat den Gewinnen eines Unternehmens dieses Staates Gewinne zugerechnet - und entsprechend besteuert -, mit denen ein Unternehmen des anderen Vertragsstaats in diesem Staat besteuert worden ist, und handelt es sich bei den zugerechneten Gewinnen um solche, die das Unternehmen des erstgenannten Staates erzielt hätte, wenn die zwischen den beiden Unternehmen vereinbarten Bedingungen die gleichen gewesen wären, die unabhängige Unternehmen miteinander vereinbaren würden, so nimmt der andere Staat eine entsprechende Änderung der dort von diesen Gewinnen erhobenen Steuer vor.“ Eine unilaterale Gegenkorrektur ist grundsätzlich die einfachste Möglichkeit, eine Doppelbesteuerung zu vermeiden. Allerdings ist der entsprechende Absatz des Art. 9 in vielen Doppelbesteuerungsabkommen nicht enthalten. Zudem bestehen in der Praxis häufig unterschiedliche Auffassungen im Hinblick auf die Fremdüblichkeit von Verrechnungspreisen, so dass unilaterale Gegenkorrekturen in diesen Fällen von den Finanzverwaltungen auch dann nicht vorgenommen werden, wenn keine verfahrensrechtlichen Hindernisse im Wege stehen.

Die Doppelbesteuerungsabkommen sehen grundsätzlich die Möglichkeit der Einleitung von Verständigungsverfahren zwischen den beteiligten Finanzverwaltungen vor. ${ }^{66}$ Im Rahmen von Verständigungsverfahren sollen sich die betroffenen Finanzverwaltungen darüber einigen, welchem Staat das Besteuerungssubstrat für den zugrundeliegenden Fall

${ }^{66}$ Vgl. Art. 25 OECD (2014), Model Tax Convention on Income and on Capital. 
zusteht. Der Antrag hat durch den Steuerpflichtigen zu erfolgen, er ist allerdings nicht Beteiligter des Verfahrens. Durch eine gute Dokumentation seiner Verrechnungspreise kann der Steuerpflichtige allerdings eine Datenlage schaffen, welche die Wahrscheinlichkeit dafür erhöht, dass das Ergebnis des Verständigungsverfahrens in seinem Sinne ausfällt. Verständigungsverfahren stellen grundsätzlich ein adäquates Mittel zur Beseitigung der Doppelbesteuerung dar. Es ist jedoch zu beachten, dass die Finanzverwaltungen im Rahmen von Verständigungsverfahren sich nur darum bemühen müssen, eine Einigung über den zugrundeliegenden Sachverhalt zu erzielen. Zwischenzeitlich wurden in vielen Doppelbesteuerungsabkommen Regelungen zu einem nachgeordneten Schiedsverfahren aufgenommen, das einen Einigungszwang für die betreffenden Finanzverwaltungen vorsieht. ${ }^{67}$ Falls dies nicht der Fall ist, kann ein Verständigungsverfahren grundsätzlich auch ohne Ergebnis von den beteiligten Finanzverwaltungen beendet werden. Die Doppelbesteuerung bliebe insoweit bestehen.

Innerhalb der Europäischen Union wurde, von den bestehenden Doppelbesteuerungsabkommen unabhängig, ein Regelwerk zu Schiedsverfahren implementiert. ${ }^{68}$ Diese Schiedsverfahren sehen einen Einigungszwang der betreffenden Finanzverwaltungen innerhalb von drei Jahren vor. Der Antrag auf Einleitung eines EU Schiedsverfahrens muss innerhalb von drei Jahren nach Bekanntwerden der die Doppelbesteuerung auslösenden Maßnahme erfolgen. Gewöhnlicherweise ist diese Maßnahme der ergehende Steuerbescheid.

Neben den unilateralen bzw. bilateralen Maßnahmen zur Beseitigung einer bereits eingetretenen Doppelbesteuerung, kann sich der Steuerpflichtige auch bereits vorab mit den beteiligten Finanzverwaltungen über die anzuwenden Verrechnungspreismethoden verständigen. Hierbei handelt es sich um sogenannte Vorabverständigungsverfahren bzw. Advance Pricing Agreements (APAs).

Die Voraussetzungen für die Durchführung von Vorabverständigungsverfahren sind in dem Merkblatt zu APAs des BMF vom 05. Oktober 2006 zusammengefasst. ${ }^{69}$ Unilaterale APAs in Deutschland sind aus Sicht der deutschen Finanzverwaltung unzulässig, da sie ausländische Finanzverwaltungen nicht binden. ${ }^{70}$

Verfahrensbeteiligte an einem APA sind auch in diesem Fall nur die beteiligten Finanzverwaltungen und nicht der Steuerpflichtige. Auf deutscher Seite ist dies das Bundeszentralamt für Steuern (BZSt). Für die Einleitung eines APAs werden Gebühren in Höhe von

${ }^{67}$ Vgl. Art. 25 Abs. 2 OECD (2014), Model Tax Convention on Income and on Capital; für eine Übersicht vgl. Eigelshoven in Vogel/Lehner, Doppelbesteuerungskommentar Art. 9.

${ }^{68}$ Vgl. Entschließung des Rates und der im Rat vereinigten Vertreter der Regierungen der Mitgliedstaaten vom 27.6.2006 zu einem Verhaltenskodex zur Verrechnungspreisdokumentation für verbundene Unternehmen in der Europäischen Union (EU TPD), Amtsblatt der Europäischen Union v. 28.7.2006, C 176/01.

${ }^{69} \mathrm{Vgl}$. Merkblatt für bilaterale oder multilaterale Verständigungsverfahren auf der Grundlage der Doppelbesteuerungsabkommen zur Erteilung verbindlicher Vorabzusagen über Verrechnungspreise zwischen international verbundenen Unternehmen, BMF IV B 4 - S- 1341 - 38/06.

${ }^{70}$ Vgl. Tz. 1.2 des o. g. Merkblatts. 
20.000 EUR von der deutschen Finanzverwaltung gem. § 178a AO erhoben. Geringere Kosten in Höhe von 15.000 EUR bzw. 10.000 EUR fallen für die Verlängerung eines bestehenden APAs bzw. die auf Antrag des Steuerpflichtigen erfolgende Änderung des APAs an. Aufgrund der umfangreichen vorzulegenden Unterlagen und der Dauer eines APA Prozesses empfiehlt sich ein APA Antrag insbesondere dann, wenn es sich um komplexe konzerninterne Transaktionen handelt, die unverändert mit hohen Volumina über einen längeren Zeitraum durchgeführt werden. In diesen Fällen (beispielsweise einem Profit Split unter Beisteuerung werthaltiger immaterieller Wirtschaftsgüter der Parteien) bietet ein APA jedoch ein Höchstmaß an Rechtssicherheit und ein sehr geringes Maß an Compliance Kosten in den folgenden Jahren. In den vergangenen Jahren ist zu beobachten, dass die Zahl der APA Anträge stetig steigt und in immer mehr Staaten die Einleitung eines APAs, beispielsweise in Indien, möglich wird.

Sofern die Summe der durch das Vorabverständigungsverfahren erfassten Geschäftsvorfälle 5.000.000 EUR bei Warentransaktionen bzw. 500.000 EUR bei Dienstleistungstransaktionen nicht überschreitet, halbieren sich die vorstehend genannten Gebühren. Zudem gelten auch geringere Anforderungen an die Aufzeichnung der konzerninternen grenzüberschreitenden der Steuerpflichtigen, § 6 GAufZV.

\subsection{Besteuerung von Betriebsstätten}

Neben der Aufteilung von Gewinnen auf rechtlich selbstständige Einheiten mittels Verrechnungspreisen kann auch die Zurechnung von Gewinnen innerhalb einer einzigen rechtlichen Einheit von Bedeutung sein, wenn diese innerhalb verschiedener Jurisdiktionen tätig ist. Dabei ist von Bedeutung, dass eine solche Aufteilung zivilrechtlich grundsätzlich nicht notwendig ist. Stattdessen haftet eine natürliche bzw. eine juristische Person mit ihrem gesamten Vermögen über Ländergrenzen hinweg.

Für steuerliche Zwecke hat sich jedoch die Betriebsstätte als Anknüpfungspunkt für Besteuerungsrechte eines Staates, in dem ein Unternehmen tätig ist, herausgebildet. Bereits in den ersten deutschen Doppelbesteuerungsabkommen wird das Besteuerungsrecht für die Besteuerung von Unternehmensgewinnen an das Vorhandensein einer Betriebsstätte in dem Tätigkeitsstaat geknüpft"11, wenn das Unternehmen dort nicht seinen Sitz hat. Trotz Weiterentwicklungen des Betriebsstättenbegriffs hat sich dieser Grundsatz bis heute nicht geändert. Im nationalen deutschen Steuerrecht begründet das Vorhandensein einer Betriebsstätte zudem eine Gewerbesteuerpflicht. Sollte ein Unternehmen in Deutschland über mehrere Betriebsstätten verfügen, ist der Gewerbeertrag zwischen den Kommunen aufzuteilen.

Zudem wird ein ausländisches Unternehmen, das weder seinen Sitz noch seine Geschäftsleitung im Inland hat, mit seinen Unternehmensgewinnen erst dann in Deutschland beschränkt steuerpflichtig, wenn es über eine in Deutschland belegene Betriebsstätte verfügt

${ }^{71}$ Vgl. Hemmelrath in Vogel/Lehner, Rz. 3. 
oder ein ständiger Vertreter bestellt ist. Die beschränkte Steuerpflicht knüpft insofern gem. $\S 1$ Abs. 4 EStG sowie $\S 2$ Nr. 1 KStG, jeweils in Verbindung mit $\S 49$ Abs. 1 Nr. 2a EStG, an die Betriebsstätte bzw. den ständigen Vertreter als Besteuerungsmerkmal an. Auch auf internationaler Ebene knüpfen Besteuerungsrechte an das Vorhandensein von Betriebsstätten in dem jeweiligen Land an. Nach Art. 7 OECD-MA sind Unternehmensgewinne nur in dem Sitzstaat des Unternehmens zu besteuern, es sei denn, dass das Unternehmen seine Geschäfte in dem anderen Staat durch eine dort belegene Betriebsstätte ausführt.

\subsubsection{Begründung von Betriebsstätten}

Eine Betriebsstätte ist gem. $§ 12 \mathrm{AO}$,jede feste Geschäftseinrichtung oder Anlage, die der Tätigkeit eines Unternehmens dient. Als Betriebstätten sind insbesondere anzusehen:

- die Stätte der Geschäftsleitung,

- Zweigniederlassungen,

- Geschäftsstellen,

- Fabrikations- oder Werkstätten,

- Warenlager,

- Ein- oder Verkaufsstellen,

- Bergwerke, Steinbrüche oder andere stehende, örtlich fortschreitende oder schwimmende Stätten der Gewinnung von Bodenschätzen,

- Bauausführungen oder Montagen, auch örtlich fortschreitende oder schwimmende, wenn

d. die einzelne Bauausführung oder Montage oder

e. eine von mehreren zeitlich nebeneinander bestehenden Bauausführungen oder Montagen oder

f. mehrere ohne Unterbrechung aufeinander folgende Bauausführungen oder Montagen länger als sechs Monate dauern.“"

Im Rahmen des vorstehend dargestellten BEPS Aktionsplans der OECD befasst sich „BEPS Action 7: Preventing the Artificial Avoidance of PE Status“72 mit der Begründung von Betriebsstätten/Vertreterbetriebsstätten. Die vorgesehenen Änderungen sind in Abschn. 2.3.2 dargestellt und in den nachfolgenden Ausführungen bereits enthalten.

International ist der Betriebsstättenbegriff gemäß Art. 5 OECD-MA definiert. Es ist zu beachten, dass der Betriebsstättenbegriff im OECD-MA enger ist, als dies im nationalen Steuerrecht der Fall ist, denn folgende Geschäftseinrichtungen begründen gem. Art. 5 Abs. 4 OECD-MA keine Betriebsstätte, auch wenn die sonstigen Tatbestandsmerkmale erfüllt sind:

72 OECD (2015), Preventing the Artificial Avoidance of Permanent Establishment Status, Action 7. 
„Einrichtungen, die ausschließlich zur Lagerung, Ausstellung oder Auslieferung von Gütern oder Waren des Unternehmens benutzt werden

- Bestände von Gütern oder Waren des Unternehmens, die ausschließlich

- zur Lagerung, Ausstellung oder Auslieferung unterhalten werden

- zu dem Zweck unterhalten werden, durch ein anderes Unternehmen bearbeitet oder verarbeitet $\mathrm{zu}$ werden

- Eine feste Geschäftseinrichtung, die ausschließlich zu dem Zweck unterhalten wird,

- für das Unternehmen Güter oder Waren einzukaufen oder Informationen zu beschaffen

- für das Unternehmen andere Tätigkeiten auszuüben.“

Voraussetzung ist, dass die Tätigkeiten vorbereitender Art sind oder eine Hilfstätigkeit darstellen. Im Falle einer Kombination dieser Tätigkeiten ist Voraussetzung, dass die gesamte kombinierte Tätigkeit ausschließlich vorbereitender Art ist oder eine Hilfstätigkeit darstellt.

Die Voraussetzung, dass die Tätigkeiten vorbereitender Art sind oder eine Hilfstätigkeit darstellen müssen um die Begründung einer Betriebsstätte zu vermeiden oder, im Falle einer Kombination dieser Tätigkeiten, die kombinierte Tätigkeit ausschließlich vorbereitender Art sein muss oder eine Hilfstätigkeit darstellt, ist durch den BEPS Action Plan 7 eingeführt worden. Die aktuellen Doppelbesteuerungsabkommen auf Basis des OECD-MA sehen dies (mit Ausnahme anderer Tätigkeiten) noch nicht vor und müssen im Rahmen des multilateralen Agreements geändert werden.

Es ist zudem zu beachten, dass Bauausführungen und Montagen gem. Art. 5 Abs. 3 OECD-MA nur dann eine Betriebsstätte begründen, wenn die Bauausführung/Montage länger als 12 Monate andauert. Die deutschen Doppelbesteuerungsabkommen weichen jedoch bei den Regelungen zur Betriebsstättenbegründung teils bedeutend von den Regelungen des OECD-MA ab. Insofern ist jeweils zu prüfen, welche Regelungen zur Betriebsstättenbegründung das jeweils einschlägige Doppelbesteuerungsabkommen vorsieht.

Neben der o.g. Betriebsstätte als Anknüpfungspunkt der Besteuerung fungiert auch der ständige Vertreter gem. $\S 13 \mathrm{AO}$ als Anknüpfungspunkt für die deutsche Besteuerung. „Ständiger Vertreter ist eine Person, die nachhaltig die Geschäfte eines Unternehmens besorgt und dabei dessen Sachweisungen unterliegt. Ständiger Vertreter ist insbesondere eine Person, die für ein Unternehmen nachhaltig

- Verträge abschließt oder vermittelt oder Aufträge einholt oder

- einen Bestand von Gütern oder Waren unterhält und davon Auslieferungen vornimmt.“

Die Entsprechung eines ständigen Vertreters im Bereich der Doppelbesteuerungsabkommen ist die Vertreterbetriebsstätte gem. Art. 5 Abs. 6 OECD-MA. Auch die Definition der Vertreterbetriebsstätte ist abkommensrechtlich enger als nach nationalem Recht. Ein Unternehmen begründet erst dann eine Betriebsstätte in dem Tätigkeitsstaat, wenn sie Ihre Geschäfte in dem Tätigkeitsstaat durch einen abhängigen Vertreter ausübt und dieser die Vollmacht besitzt für das Unternehmen Verträge abzuschließen oder gewöhnlich die 
wesentliche Rolle beim Vertragsabschluss übernimmt, die dann regelmäßig ohne substanzielle Änderungen vom Unternehmen abgeschlossen werden. Ein Unternehmen begründet jedoch nach BEPS keine Betriebstätte in dem Tätigkeitsstaat, wenn es seine Geschäftstätigkeit durch einen unabhängigen Vertreter ausübt, der im Rahmen seiner ordentlichen Geschäftstätigkeit handelt. Diese Ausnahme gilt jedoch nach BEPS nicht für Transaktionen mit verbundenen Unternehmen, wenn der Vertreter ausschließlich oder fast ausschließlich für verbundene Unternehmen tätig wird. Unternehmen gelten als verbundene Unternehmen wenn direkte oder indirekte Beteiligungen von mehr als $50 \%$ vorliegen.

Auf das Kriterium der Abschlussvollmacht wird nach BEPS wie in Abschn. 2.3.2 beschrieben nicht mehr abgestellt. Dementsprechend können in Zukunft auch Kommissionäre, sofern sie die sonstigen Kriterien erfüllen, Vertreterbetriebsstätten für den Kommittenten begründen was gem. den bisherigen Doppelbesteuerungsabkommen gewöhnlicherweise nicht der Fall war. Insbesondere Kommissionärsstrukturen sind dementsprechend dahingehend zu überprüfen, ob auch nach Änderung der Doppelbesteuerungsabkommen durch das multilaterale Agreement weiterhin keine Vertreterbetriebsstätten begründet werden.

Die Regelungen der OECD zur Begründung einer Betriebsstätte werden in den einzelnen Mitgliedsstaaten nicht vollständig einheitlich ausgelegt. Generell gilt, dass die Bundesrepublik Deutschland den Betriebsstättenbegriff im Rahmen der Regelungen der Doppelbesteuerungsabkommen eher eng auslegt. Viele OECD-Staaten und insbesondere nicht OECD-Staaten legen den in den Doppelbesteuerungsabkommen definierten Betriebsstättenbegriff jedoch zum Teil erheblich weiter aus. Allgemein bleibt festzuhalten, dass beispielsweise die Frage der Verfügungsmacht über eine feste Geschäftseinrichtung nicht zwangsläufig an einen rechtlichen Mietvertrag oder an das Eigentum anknüpft. Eine Verfügungsmacht über die genutzten Räume kann beispielsweise auch dadurch begründet werden, dass ein Dienstleister dauerhaft die Räume seines ausländischen Auftraggebers nutzen kann.

Im Folgenden werden die Grundsätze für die Zurechnung von Gewinnen zu einer Betriebsstätte dargestellt.

\subsubsection{Zuordnung von Gewinnen zu einer Betriebsstätte}

Wie vorstehend dargestellt führt die Begründung einer Betriebsstätte im Ausland dazu, dass Besteuerungsrechte zwischen einzelnen Staaten aufgeteilt werden. Damit kommt der Höhe der Unternehmensgewinne, die einer Betriebsstätte zuzurechnen sind, eine besondere Bedeutung zu. Dabei stellt sich zuallererst die Frage, welche Gewinne eines Unternehmens einer Betriebsstätte überhaupt zugerechnet werden müssen. Nach dem Attraktivitätsprinzip werden sämtliche Gewinne eines Unternehmens in einem Vertragsstaat, in dem eine Betriebsstätte vorhanden ist, dieser Betriebsstätte zugerechnet. Grundsätzlich gilt jedoch, dass in den Doppelbesteuerungsabkommen die dem OECD-MA folgen, keine Attraktivkraft der Betriebsstätte vorgesehen ist. Dementsprechend sind einer Betriebsstätte nur die Gewinne steuerlich zuzurechnen, die dieser Betriebsstätte auch wirtschaftlich zuzurechnen sind. 
Da es sich bei der Abgrenzung der Gewinne einer Betriebsstätte um die Abgrenzung von Gewinnen innerhalb einer rechtlichen Einheit für Zwecke der Besteuerung handelt, kann die Gewinnermittlung einer Betriebsstätte nicht wie bei rechtlich selbstständigen Unternehmen an das handelsrechtliche Ergebnis anknüpfen. Auch der Abschluss zivilrechtlich wirksamer Verträge zwischen Stammhaus und Betriebsstätte ist, da es sich um eine einzige rechtliche Einheit handelt, nicht möglich. Dementsprechend ist eine zentrale Frage der Zuordnung von Gewinnen zu Betriebsstätten, ob und wie die rechtliche Unselbstständigkeit der Betriebsstätte berücksichtigt werden sollte. Den Grundsatz der Gewinnzuordnung bildet der Fremdvergleich. Die Gewinnzuordnung bei Betriebsstätten war jahrzehntelang geprägt durch die Berücksichtigung der Tatsache, dass eine Betriebsstätte kein rechtlich selbstständiges Unternehmen, sondern ein unselbstständiger Teil des Gesamtunternehmens ist. Die Theorie der eingeschränkten Selbstständigkeit wurde auch durch die deutsche Finanzverwaltung in den Betriebsstätten-Verwaltungsgrundsätzen vertreten. Die Theorie der eingeschränkten Selbstständigkeit der Betriebsstätte wurde jedoch in den letzten Jahren von dem „Seperate Entity Approach“ der OECD abgelöst. Gemäß des Seperate Entity Approachs oder Authorized OECD Approachs wird die Betriebsstätte für Zwecke der Gewinnzuordnung behandelt als wäre sie ein rechtlich selbstständiges Unternehmen. Während aufgrund der Theorie der eingeschränkten Selbstständigkeit der Betriebsstätte beispielsweise eine fiktive Vermietung von Grundstücken durch das Stammhaus an die Betriebsstätte zu keiner Gewinnrealisierung, sondern ausschließlich zu einer Kostenabrechnung, führen würde, ist aufgrund der Behandlung der Betriebsstätte wie ein rechtlich selbstständiges Unternehmen auch eine Gewinnrealisierung bei einer solchen „Vermietung“ von Wirtschaftsgütern des Stammhauses an die Betriebsstätte möglich.

Die Zuordnung von Gewinnen zu Betriebsstätten wird durch Art. 7 OECD-MA begrenzt. Die Umsetzung des Authorized OECD Approachs machte eine Änderung des Wortlauts des Art. 7 OECD-MA notwendig. Dementsprechend ist der Art. 7 OECD-MA im Jahr 2010 geändert worden. Dies bedeutet jedoch, dass die auf Basis des alten OECDMA abgeschlossenen Doppelbesteuerungsabkommen den Authorized OECD Approach noch nicht berücksichtigen. In das nationale deutsche Steuerrecht ist der Authorized OECD Approach mit Wirkung zum 1. Januar 2013 übernommen worden. § 1 AStG wurde insofern geändert und ausdrücklich auch auf die Gewinnermittlung von Betriebsstätten angewendet. Eine Ausnahme von der Gewinnermittlung nach diesem Ansatz gibt es nur noch in den Fällen, in denen ein Doppelbesteuerungsabkommen existiert und der andere Vertragsstaat die Gewinnermittlung der Betriebsstätte aufgrund der Theorie der eingeschränkten Selbstständigkeit der Betriebsstätte durchführt und dies Auswirkungen (geringere Besteuerungsrechte für die Bundesrepublik Deutschland) auf die Zuordnung von Gewinnen zwischen der Betriebsstätte und dem Stammhaus hat.

Da der deutsche Gesetzgeber die Gewinnzuordnung bei Betriebsstätten nach dem Authorized OECD Approach zum Regelfall gemacht hat, werden im Folgenden die Grundzüge der Einkommensermittlung einer Betriebsstätte nach dem Authorized OECD Approach dargestellt. Grundsätzlich geht der Authorized OECD Approach nach einem zweistufigen Verfahren vor. In einem ersten Schritt werden die Funktionen der Betriebstätte bestimmt. Im Anschluss hieran werden die übernommenen Risiken und die hierfür notwendige Kapitalausstattung der Betriebsstätte bestimmt. In einem zweiten Schritt wer- 
den auf Grundlage des ersten Schrittes die Geschäftsbeziehungen (sog. Dealings) zwischen dem Stammhaus und der Betriebsstätte bestimmt. Dieser Ansatz ist folgendermaßen in $\S 1$ Abs. 5 AStG übernommen worden:

„Zur Anwendung des Fremdvergleichsgrundsatzes ist eine Betriebsstätte wie ein eigenständiges und unabhängiges Unternehmen zu behandeln, es sei denn, die Zugehörigkeit der Betriebsstätte zum Unternehmen erfordert eine andere Behandlung. Um die Betriebsstätte wie ein eigenständiges und unabhängiges Unternehmen zu behandeln, sind ihr in einem ersten Schritt zuzuordnen:

1. die Funktionen des Unternehmens, die durch ihr Personal ausgeübt werden (Personalfunktionen),

2. die Vermögenswerte des Unternehmens, die sie zur Ausübung der ihr zugeordneten Funktionen benötigt,

3. die Chancen und Risiken des Unternehmens, die sie auf Grund der ausgeübten Funktionen und zugeordneten Vermögenswerte übernimmt, sowie

4. ein angemessenes Eigenkapital (Dotationskapital).

Auf der Grundlage dieser Zuordnung sind in einem zweiten Schritt die Art der Geschäftsbeziehungen zwischen dem Unternehmen und seiner Betriebsstätte und die Verrechnungspreise für diese Geschäftsbeziehungen zu bestimmen“.

Wie der Ausgestaltung von $\S 1$ Abs. 5 AStG entnommen werden kann, wird die Betriebsstätte auch bei einer Einkünftezurechnung nach dem neuen Authorized OECD Approach nicht zwangsläufig wie ein rechtlich selbstständiges Unternehmen behandelt. Beispielsweise könnte es problematisch sein, Auftragsforschung durch eine Betriebsstätte durchführen zu lassen. Da die Betriebsstätte nicht aufgrund eines Vertrags risikolos gestellt werden kann, sondern sich die der Betriebsstätte zugeordneten Vermögenswerte und die Chancen und Risiken der Betriebsstätte nach den Funktionen des der Betriebsstätte zugeordneten Personals bestimmen, muss beim Aufsetzen einer solchen Planung verstärkt darauf geachtet werden, dass beispielsweise die strategischen Entscheidungen ausschließlich durch das Stammhaus durchgeführt werden.

Auch die Disposition von Fremdkapital ist nicht so frei wie bei einem rechtlich selbstständigen Unternehmen. Während ein rechtlich selbstständiges Unternehmen grundsätzlich über die eigene Kapitalausstattung frei entscheiden kann und steuerliche Regelungen ausschließlich die steuerliche Abzugsfähigkeit der Zinsen beschränken (in Deutschland bspw. durch die Anwendung der Zinsschranke gem. § 4h EStG), wird der Betriebsstätte ein angemessenes Eigenkapital zugerechnet. Es besteht insofern keine vollständige Dispositionsfreiheit darüber, wie die Betriebsstätte mit Eigenkapital ausgestattet werden soll.

Die neuen Regelungen des $\S 1 \mathrm{AStG}$ sind durch den Erlass einer Rechtsverordnung vom 13. Oktober 2014 weiter präzisiert worden. ${ }^{73}$ Die Rechtsverordnung gilt mit Wirkung für Geschäftsjahre die nach dem 01.01.2015 beginnen. Die Zuordnung von Einkünften zu einer Betriebsstätte ist gem. $§ 1$ Abs. 2 der Rechtsverordnung folgendermaßen vorzunehmen:

„Auf Grundlage der Funktions- und Risikoanalyse der Geschäftstätigkeit der Betriebsstätte

${ }^{73}$ Bundesgesetzblatt Jahrgang 2014 Teil I Nr. 47, ausgegeben zu Bonn am 17. Oktober 2014 S. 1603. 
1. sind die Personalfunktionen ( $§ 1$ Abs. 5 Satz 3 Nr. 1 AStG), die der Betriebsstätte oder dem übrigen Unternehmen zuzuordnen sind, festzustellen, insbesondere die maßgeblichen Personalfunktionen,

2. sind der Betriebsstätte, ausgehend von den maßgeblichen Personalfunktionen, Vermögenswerte ( $§ 1$ Abs. 5 Satz 3 Nr. 2 AStG) sowie Chancen und Risiken ( 1 Abs. 5 Satz 3 Nr. 3 AStG) zuzuordnen,

3. ist der Betriebsstätte, ausgehend von den ihr zugeordneten Vermögenswerten sowie von den ihr zugeordneten Chancen und Risiken, ein Dotationskapital ( $\$ 1$ Abs. 5 Satz 3 Nr. 4 AStG) zuzuordnen,

4. sind der Betriebsstätte Passivposten zuzuordnen, soweit dies auf Grund der Zuordnung von Vermögenswerten, von Chancen und Risiken sowie von Dotationskapital erforderlich ist,

5. sind der Betriebsstätte Geschäftsvorfälle des Unternehmens mit unabhängigen Dritten und mit nahestehenden Personen im Sinne des $\S 1$ Abs. 2 des Außensteuergesetzes zuzuordnen und

6. sind die anzunehmenden schuldrechtlichen Beziehungen im Sinne des $\S 1$ Abs. 4 Satz 1 Nr. 2 des Außensteuergesetzes zu bestimmen, die die Betriebsstätte zum übrigen Unternehmen unterhält.“

Für jede Betriebsstätte hat der Steuerpflichtige zudem am Anfang eines Wirtschaftsjahres eine Hilfs- und Nebenrechnung aufzustellen. Diese Hilfs- und Nebenrechnung ist zu Beginn eines jeden Wirtschaftsjahres aufzustellen und fortzuschreiben. Sie beinhaltet sowohl die Aktiv- und Passivposten die der Betriebsstätte zuzuordnen sind als auch fiktive Betriebseinnahmen und Betriebsausgaben aufgrund anzunehmender schuldrechtlicher Beziehungen zwischen Stammhaus und Betriebsstätte. Dies können beispielsweise fiktive Mieteinkünfte des Stammhauses für die temporäre Überlassung von Wirtschaftsgütern an die Betriebsstätte sein. Zur Erfüllung der Dokumentationsvorschriften nach $§ 90$ Abs. 3 AO hat der Steuerpflichtige zudem auf Anforderung der Finanzverwaltung die Gründe für die Zuordnung der jeweiligen Bestandteile sowie auch die Gründe für die Annahme der jeweiligen Geschäftsbeziehungen darzulegen.

Die Rechtsverordnung beinhaltet darüber hinaus noch weitere Sonderregelungen für Bau- und Montagebetriebsstätten, für Förderbetriebstätten sowie Versicherungsbetriebsstätten. Es ist zudem beabsichtigt, die Rechtsverordnung durch vom Bundesfinanzministerium erlassene Verwaltungsgrundsätze weiter zu konkretisieren. Ein Diskussionsentwurf der Verwaltungsgrundsätze Betriebsstättengewinnaufteilung (VWG BsGa) wurde am 18. März 2016 veröffentlicht.

Die deutsche Finanzverwaltung sieht sich bei der Umsetzung des Authorized OECD Approachs insofern in einer Vorreiterrolle, als dass die Neuregelungen in anderen OECDStaaten überwiegend noch nicht in nationales Recht umgesetzt worden sind. Da auch viele Nicht-OECD-Staaten wie Brasilien oder China den Authorized OECD Approach nicht unterstützen, sind insofern Konflikte vorhersehbar. Kritisch anzumerken ist zudem, dass die Rechtsverordnung in einigen Bereichen (bspw. im Bereich der Zuordnung von Dotationskapital) unterschiedliche Zuordnungsregeln für inländische Betriebsstätten ausländischer Unternehmen und ausländische Betriebsstätten inländischer Unternehmen zu Lasten 
ausländischer Finanzverwaltungen vorsieht. Ob eine Doppelbesteuerung vor diesem Hintergrund in allen Fällen vermieden werden kann, bleibt abzuwarten.

\section{Literatur}

BFH, Urteil vom 17.10.2001 - Az. I R 103-00. Konzernverrechnungspreise als vGA einer Vertriebsgesellschaft. BStB1 II 2004, S. 171

BFH, Urteil vom 19.01.1994 - Az. IR 93/93. Nahestehende Person i. S. d. AStG; „eigenes Interesse“ an der Einkunftserzielung kann auch ein persönliches Interesse sein; Bedeutung der Währung für den ,angemessenen Zins“. BStB1 II 1994, S. 725

BFH, Urteil vom 11.10.2012. Verdeckte Gewinnausschüttung: Sperrwirkung von Art. 6 Abs. 1 DBA- Niederlande 1959 (Art. 9 Abs. 2 OECD-MA) gegenüber Sonderbedingungen bei beherrschenden Gesellschaftern - Gewinnabgrenzung - Az. IR 75/11

BMF, Schreiben vom 12.4.2005. Grundsätze für die Prüfung der Einkunftsabgrenzung zwischen nahestehenden Personen mit grenzüberschreitenden Geschäftsbeziehungen in Bezug auf Ermittlungs- und Mitwirkungspflichten, Berichtigungen sowie auf Verständigungs- und EU Schiedsverfahren (Verwaltungsgrundsätze-Verfahren). IV B 4 - S 1341 - 1/05. BStB1 2005 I, S. 570

BMF Schreiben vom 13.10.2010. Grundsätze für die Prüfung der Einkunftsabgrenzung zwischen nahe stehenden Personen in Fällen von grenzüberschreitenden Funktionsverlagerungen (Verwaltungsgrundsätze Funktionsverlagerung). IV B 5 - S 1341 - 08 - 10003. BStB1 2010 I, S. 774.

BMF Schreiben vom 14.05.2004. Grundsätze zur Anwendung des Außensteuergesetzes. IV B 4 -S 1340 - 11/04. BStB1 2004 I Sondernummer I /2004.

Bundesgesetzblatt Jahrgang 2014 Teil I Nr. 47, ausgegeben zu Bonn am 17. Oktober 2014 S. 1603

Eigelshoven, A., Art. 9, 2015. In Doppelbesteuerungsabkommen Kommentar 6. Aufl., hrsg. Vogel, K., Lehner, M. C.H. Beck

Finanzgericht Köln, Urteil vom 22.08.2007 zum Doppelbesteuerungsabkommen mit Großbritannien, Az. 13 K 647/03 Entscheidungen der Finanzgerichte 2008, S. 161

Entschließung des Rates und der im Rat vereinigten Vertreter der Regierungen der Mitgliedstaaten vom 27.6.2006 zu einem Verhaltenskodex zur Verrechnungspreisdokumentation für verbundene Unternehmen in der Europäischen Union (EU TPD), Amtsblatt der Europäischen Union v. 28.7.2006, C 176/01

Flick/Wassermeyer/Baumhoff/Schönfeld (Hrsg.), Außensteuerrecht, Dezember 2014, Verlag Dr. Otto Schmidt, Köln

Hemmelrath, A. Art. 7, 2015. In Doppelbesteuerungsabkommen Kommentar 6. Aufl., hrsg. Vogel, K., Lehner, M. C.H. Beck

Kroppen, H.-K., Nientimp, A. 2011. Generalthema I: Funktionsverlagerung, 650, IStR. Beck- Online

Kroppen, Handbuch Internationale Verrechnungspreise, Lose Blattsammlung, Verlag Dr. Otto Schmidt, Köln

Merkblatt für bilaterale oder multilaterale Verständigungsverfahren auf der Grundlage der Doppelbesteuerungsabkommen zur Erteilung verbindlicher Vorabzusagen über Verrechnungspreise zwischen international verbundenen Unternehmen, BMF IV B 4 - S- 1341 - 38/06

OECD (Hrsg.). 22. Juli, 2010. Transfer Pricing Guidelines for Multinational Enterprises and Tax Administrations

OECD (2014), Model Tax Convention on Income and on Capital: Condensed Version 2014, OECD Publishing, Paris. („OECD (2014), Model Tax Convention on Income and on Capital“) http:// dx.doi.org/10.1787/mtc_cond-2014-en

OECD (2015), Preventing the Artificial Avoidance of Permanent Establishment Status, Action 7-2015 Final Report, OECD/G20 Base Erosion and Profit Shifting Project, OECD Publishing, Paris. („OECD (2015), Preventing the Artificial Avoidance of Permanent Establishment Status, Action 7“) http://dx.doi.org/10.1787/9789264241220-en 
OECD (2015), Aligning Transfer Pricing Outcomes with Value Creation, Actions 8-10 - 2015 Final Reports, OECD/G20 Base Erosion and Profit Shifting Project, OECD Publishing, Paris. („OECD (2015), Aligning Transfer Pricing Outcomes with Value Creation, Actions 8-10“) http://dx.doi. org/10.1787/9789264241244-en

OECD (2015), Transfer Pricing Documentation and Country-by-Country Reporting, Action 13 2015 Final Report, OECD/G20 Base Erosion and Profit Shifting Project, OECD Publishing, Paris. („OECD (2015), Transfer Pricing Documentation and Country-by-Country Reporting, Action 13“) http://dx.doi.org/10.1787/9789264241480-en

OECD Webcast Unterlagen 5. Oktober 2015, „Launch of the final BEPS Reports“, S. 51

Schreiber, R., Nientimp, A. (Hrsg.). 2015. Verrechnungspreise, 6. Aufl. NWB Verlag GmbH \& Co. KG, Herne

Vögele, A., Borstell, T. \& Engler, G., Verrechnungspreise, 4. Auflage 2015, C.H. Beck München

Claas Buurman arbeitet als Senior Manager im Team der Service Line Verrechnungspreise von Deloitte am Standort Berlin. Herr Buurman ist Steuerberater und Diplom Volkswirt und hat Volkswirtschaftslehre an der Universität Göttingen studiert. Seit Beginn seiner Tätigkeit bei Deloitte im Jahre 2008 berät Herr Buurman multinationale Unternehmen in Fragen des internationalen Steuerrechts. Seit 2009 ist er im Team der Service Line Verrechnungspreise von Deloitte tätig. Zu seinen Schwerpunkten zählen insbesondere die Planung, Implementierung und Dokumentation von Verrechnungspreissystemen sowie die Verteidigung von Verrechnungspreissystemen in Betriebsprüfungen.

Susanne Tomson ist als Senior Manager im Bereich Verrechnungspreise bei PwC in Köln tätig. Sie ist Rechtsanwältin, Fachanwältin für Steuerrecht und hat einen Master of Business Law (MBL). Susanne Tomson hat 10 Jahre Erfahrung im Bereich Transfer Pricing und International Taxation und berät Mandanten bei der Konzeptionierung, Implementierung und Dokumentation von Verrechnungspreissystemen sowie bei Unternehmensumstrukturierungen im Hinblick auf Verrechnungspreisthemen und Fragen des internationalen Steuerrechts. Ein weiterer Beratungsschwerpunkt liegt in der Verteidigung von Verrechnungspreisen in steuerlichen Betriebsprüfungen und Verständigungsverfahren bzw. Advance Pricing Agreements. Susanne Tomson kommentiert zu Kap. V der OECD-Leitlinien „Verrechnungspreisdokumentation und Country-by-Country Reporting“ in Kroppen, Handbuch Internationale Verrechnungspreise und ist Autorin einer Vielzahl von Veröffentlichungen in Fachzeitschriften.

Open Access Dieses Kapitel wird unter der Creative Commons Namensnennung-Nicht kommerziell 2.5 International Lizenz (http://creativecommons.org/licenses/by-nc/2.5/deed.de) veröffentlicht, welche für nicht kommerzielle Zwecke die Nutzung, Verbreitung und Wiedergabe in jeglichem Medium und Format erlaubt, sofern Sie den/die ursprünglichen Autor(en), den Titel des Werks und die Quelle ordnungsgemäß nennen, einen Link zur Creative Commons Lizenz beifügen und im Falle einer Abwandlung durch einen entsprechenden Hinweis deutlich erkennbar machen, dass Änderungen vorgenommen wurden.

Die in diesem Kapitel enthaltenen Bilder und sonstiges Drittmaterial unterliegen ebenfalls der genannten Creative Commons Lizenz, sofern sich aus der Abbildungslegende nichts anderes ergibt. Sofern das betreffende Material nicht unter der genannten Creative Commons Lizenz steht und die betreffende Handlung nicht nach gesetzlichen Vorschriften erlaubt ist, ist auch für die oben aufgeführten nichtkommerziellen Weiterverwendungen des Materials die Einwilligung des jeweiligen Rechteinhabers einzuholen. 